\title{
Calculations of Hydrogen Associative Desorption on Mono- and Bimetallic Catalysts
}

Huiling Zheng, ${ }^{\mathrm{a}, \mathrm{b}, \dagger}$ Hao Li, ${ }^{\mathrm{b}, \mathrm{c}, \dagger}$ Weiyu Song, ${ }^{\mathrm{a}}$ Zhen Zhao, ${ }^{\mathrm{a}, \mathrm{d},{ }^{*}}$ and Graeme Henkelman ${ }^{\mathrm{b}, *}$

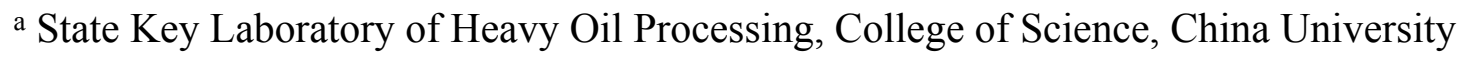
of Petroleum-Beijing, Chang Ping District, Beijing 102249, China

${ }^{\mathrm{b}}$ Department of Chemistry and the Oden Institute for Computational Engineering and Sciences, University of Texas at Austin, Austin, Texas 78712-0231, USA

c Present address: Department of Physics, Technical University of Denmark, 2800 Kongens Lyngby, Denmark

${ }^{\mathrm{d}}$ Institute of Catalysis for Energy and Environment, Shenyang Normal University, Shenyang 110034, China

$\dagger$ These authors contributed equally to this work.

${ }^{*}$ Corresponding Authors

E-mail: zhenzhao@cup.edu.cn (Z. Zhao); zhaozhen1586@163.com (Z. Zhao); henkelman@utexas.edu (G. Henkelman); 


\section{Supporting Information}

Table S1. Desorption energies and mechanisms on Pt and Pt-Au surfaces by different methods.

\begin{tabular}{ccccccc}
\hline \multirow{2}{*}{ Surface } & \multicolumn{2}{c}{$\mathrm{PBE}$} & \multicolumn{2}{c}{$\mathrm{RPBE}$} & \multicolumn{2}{c}{ PBE-D2 } \\
\cline { 2 - 7 } & $\mathrm{E}_{\mathrm{des}} / \mathrm{eV}$ & Mechanism & $\mathrm{E}_{\mathrm{des}} / \mathrm{eV}$ & Mechanism & $\mathrm{E}_{\mathrm{des}} / \mathrm{eV}$ & Mechanism \\
\hline $\mathrm{Pt}$ & 0.79 & 2 & 0.50 & 2 & 0.91 & 2 \\
$\mathrm{Pt}_{1}-\mathrm{Au}_{\mathrm{x}}$ & 0.25 & 1 & -0.12 & 1 & 0.42 & 1 \\
$\mathrm{Pt}_{2}-\mathrm{Au}_{\mathrm{x}}$ & 0.63 & 1 & 0.18 & 1 & 0.70 & 1 \\
$\mathrm{Pt}_{3}-\mathrm{Au}_{\mathrm{x}}$ & 0.63 & 1 & 0.14 & 1 & 0.66 & 1 \\
$\mathrm{Pt}_{4}-\mathrm{Au}_{\mathrm{x}}$ & 0.76 & 1 & 0.27 & 1 & 0.76 & 1 \\
$\mathrm{Pt}_{\mathrm{m}}-\mathrm{Au}_{\mathrm{x}}$ & 1.30 & 2 & 0.93 & 2 & 1.29 & 2 \\
\hline
\end{tabular}




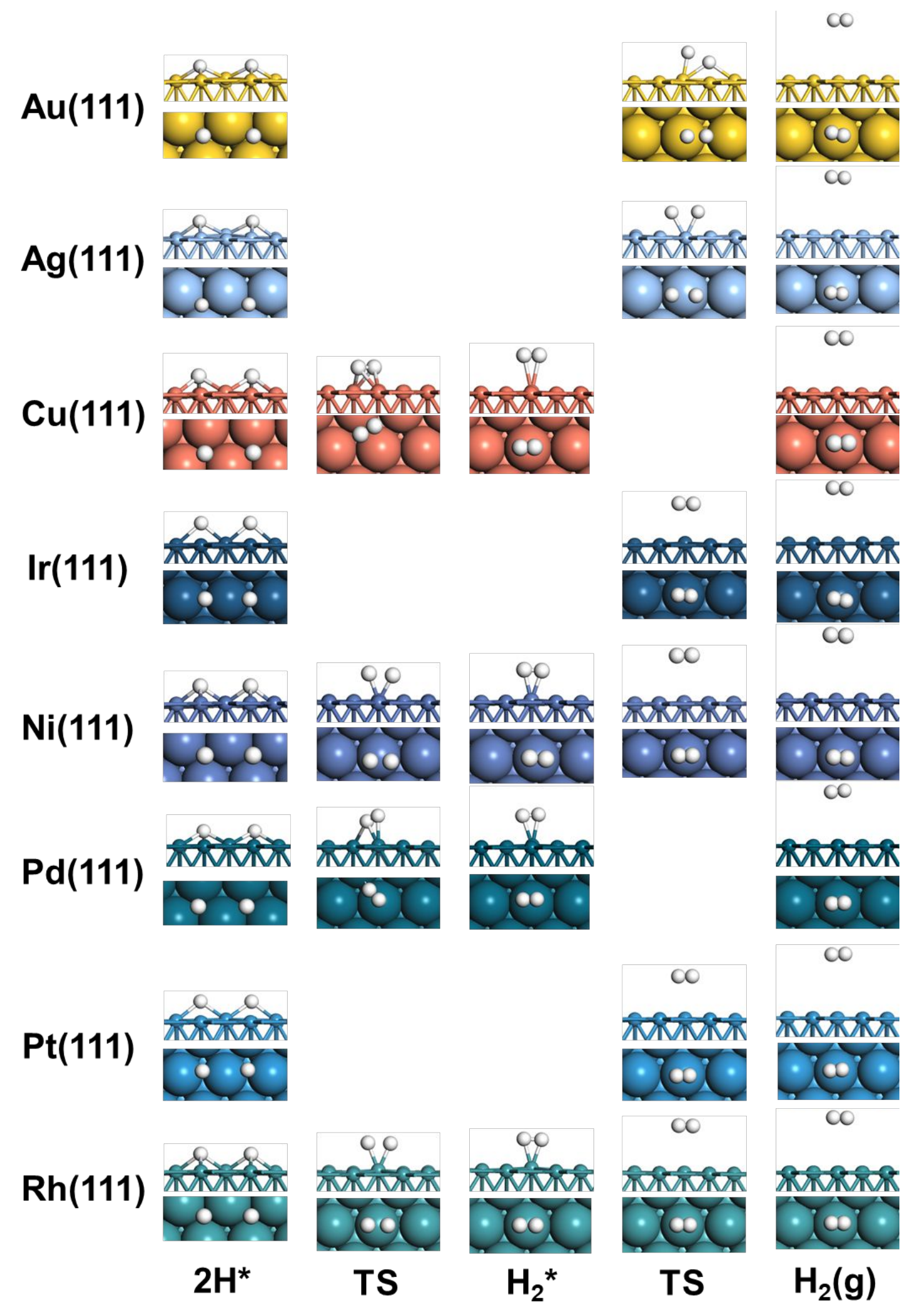

Figure S1. Hydrogen desorption pathways on the monometallic surfaces. Yellow, silver, red, deep blue, purple, deep green, blue, green, and white spheres represent $\mathrm{Au}$, $\mathrm{Ag}, \mathrm{Cu}, \mathrm{Ir}, \mathrm{Ni}, \mathrm{Pd}, \mathrm{Pt}, \mathrm{Rh}$, and $\mathrm{H}$, respectively. 


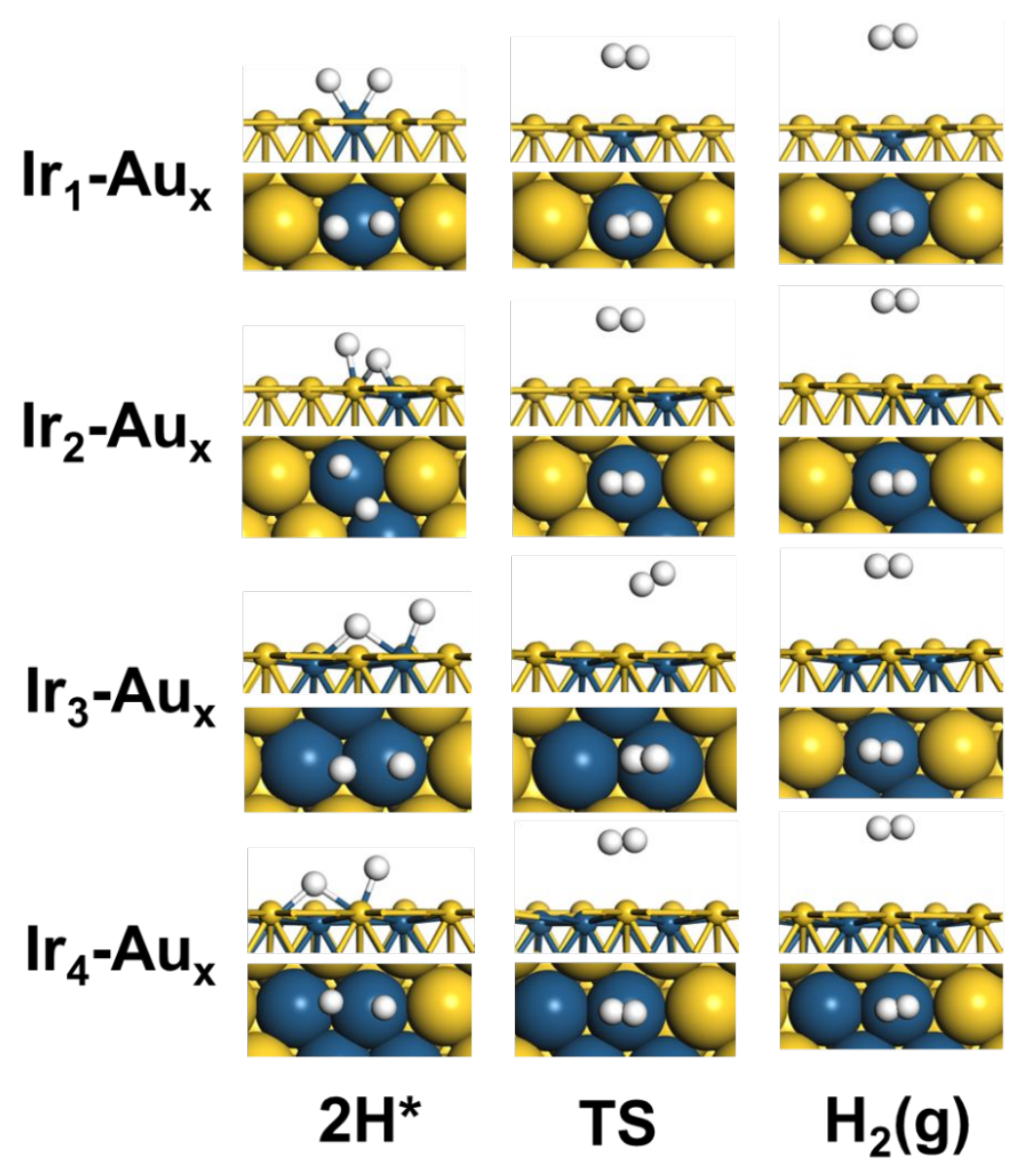

Figure S2. Hydrogen desorption pathways on Ir-Au surfaces. Yellow, deep blue, and white spheres represent $\mathrm{Au}$, Ir, and $\mathrm{H}$, respectively. 


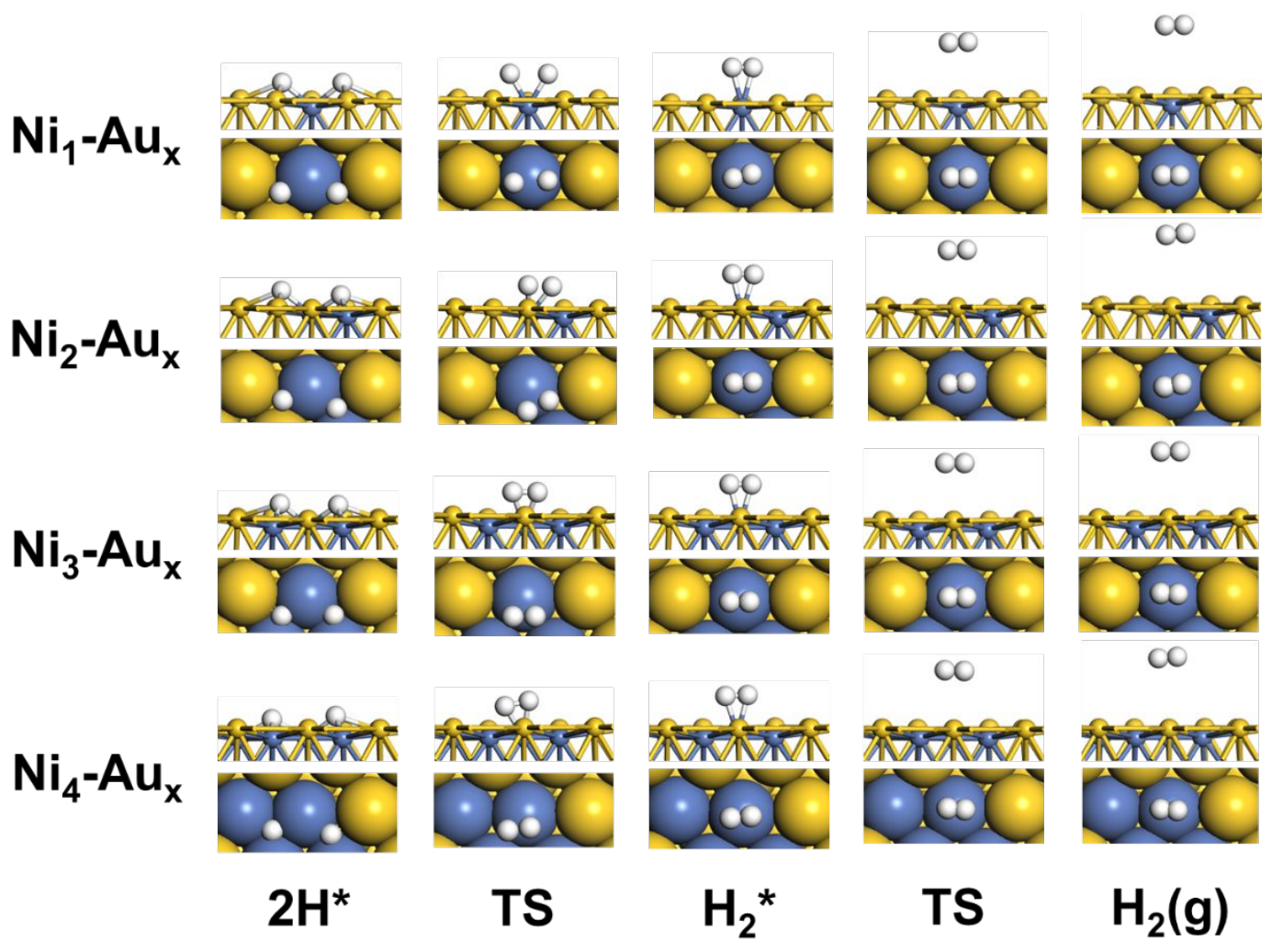

Figure S3. Hydrogen desorption pathways on Ni-Au surfaces. Yellow, purple, and white spheres represent $\mathrm{Au}, \mathrm{Ni}$, and $\mathrm{H}$, respectively. 


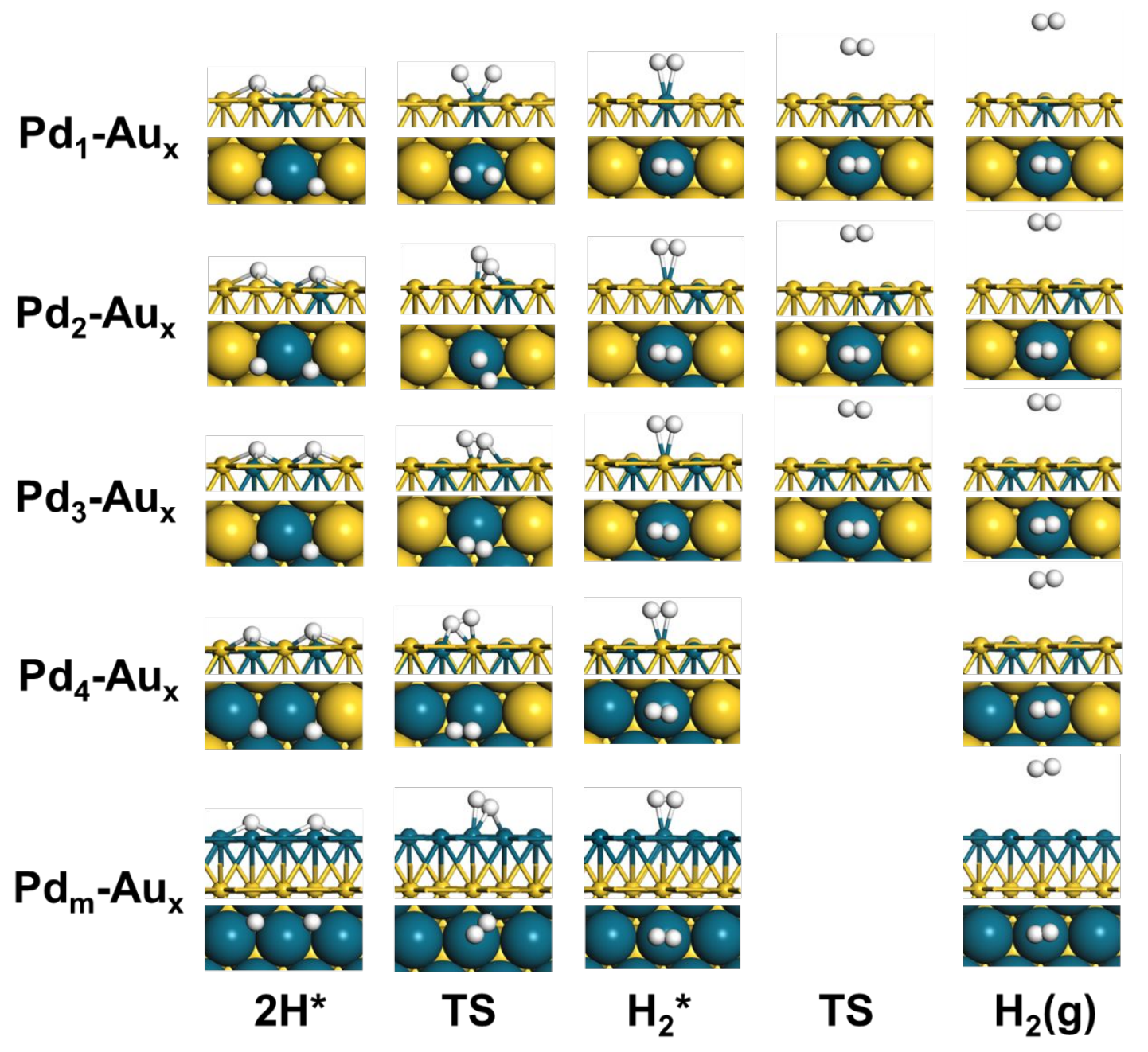

Figure S4. Hydrogen desorption pathways on Pd-Au surfaces. Yellow, deep green, and white spheres represent $\mathrm{Au}, \mathrm{Pd}$, and $\mathrm{H}$, respectively. 


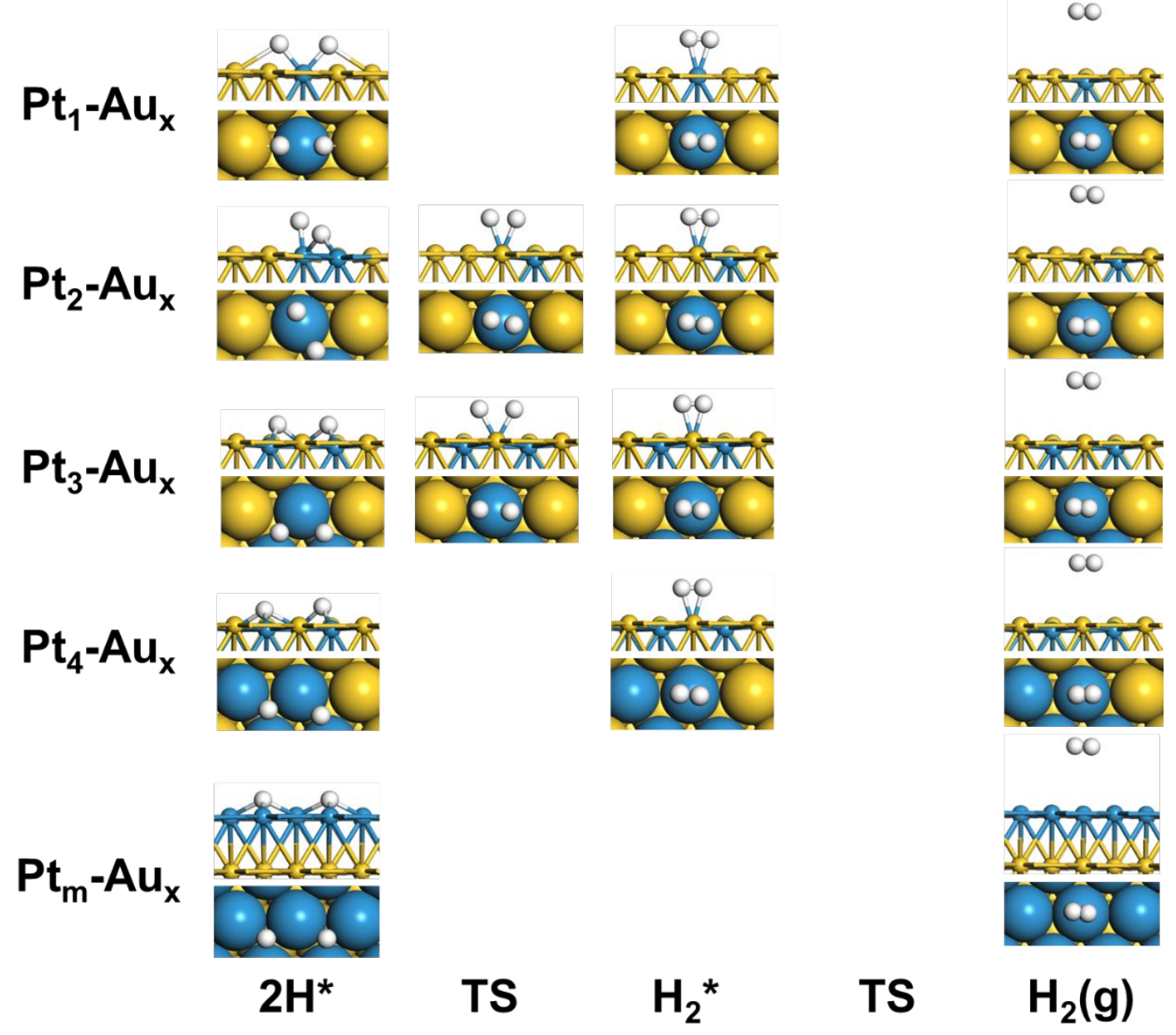

Figure S5. Hydrogen desorption pathways on Pt-Au surfaces. Yellow, blue, and white spheres represent $\mathrm{Au}, \mathrm{Pt}$, and $\mathrm{H}$, respectively. 


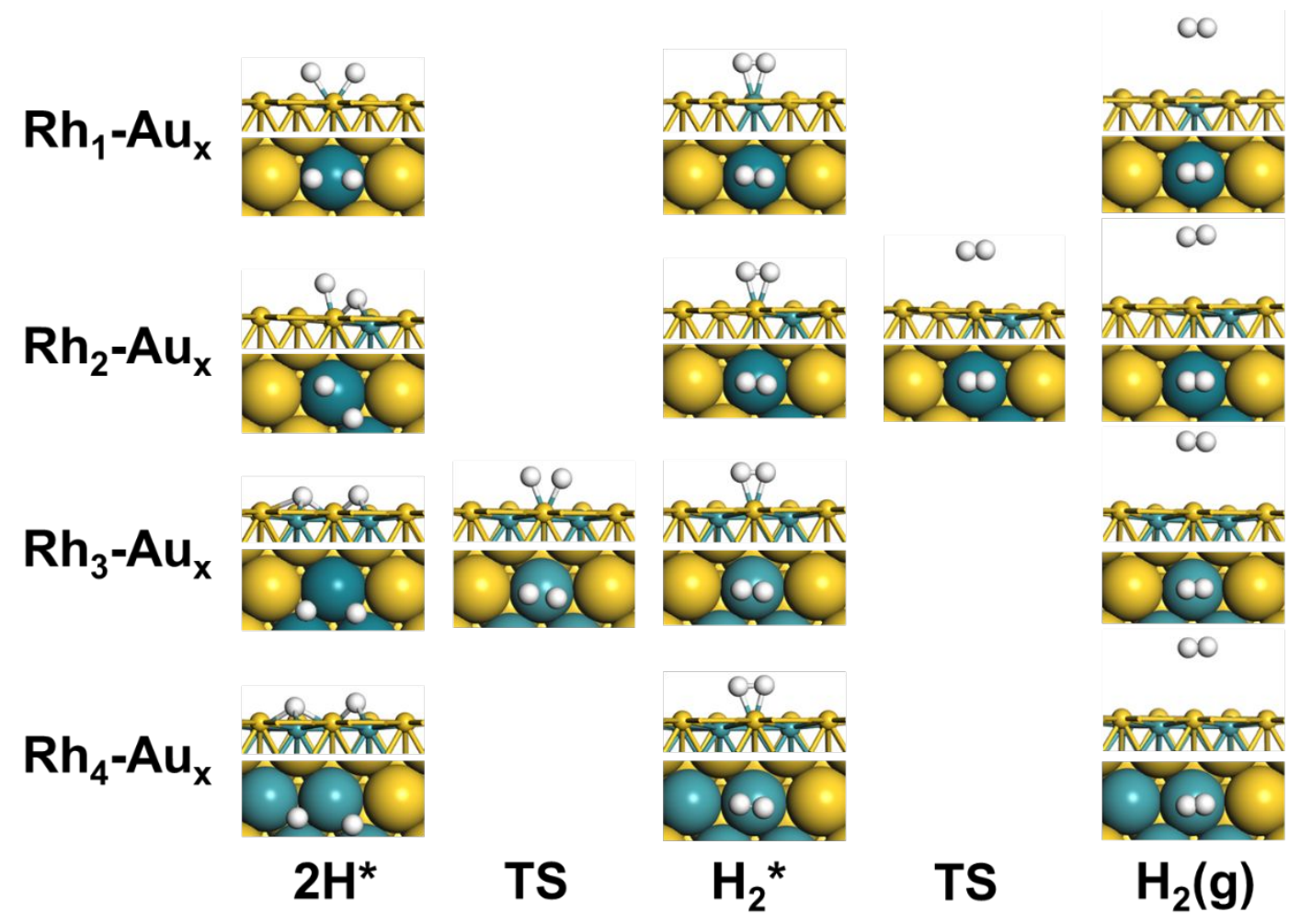

Figure S6. Hydrogen desorption pathways on Rh-Au surfaces. Yellow, green, and white spheres represent $\mathrm{Au}, \mathrm{Rh}$, and $\mathrm{H}$, respectively. 


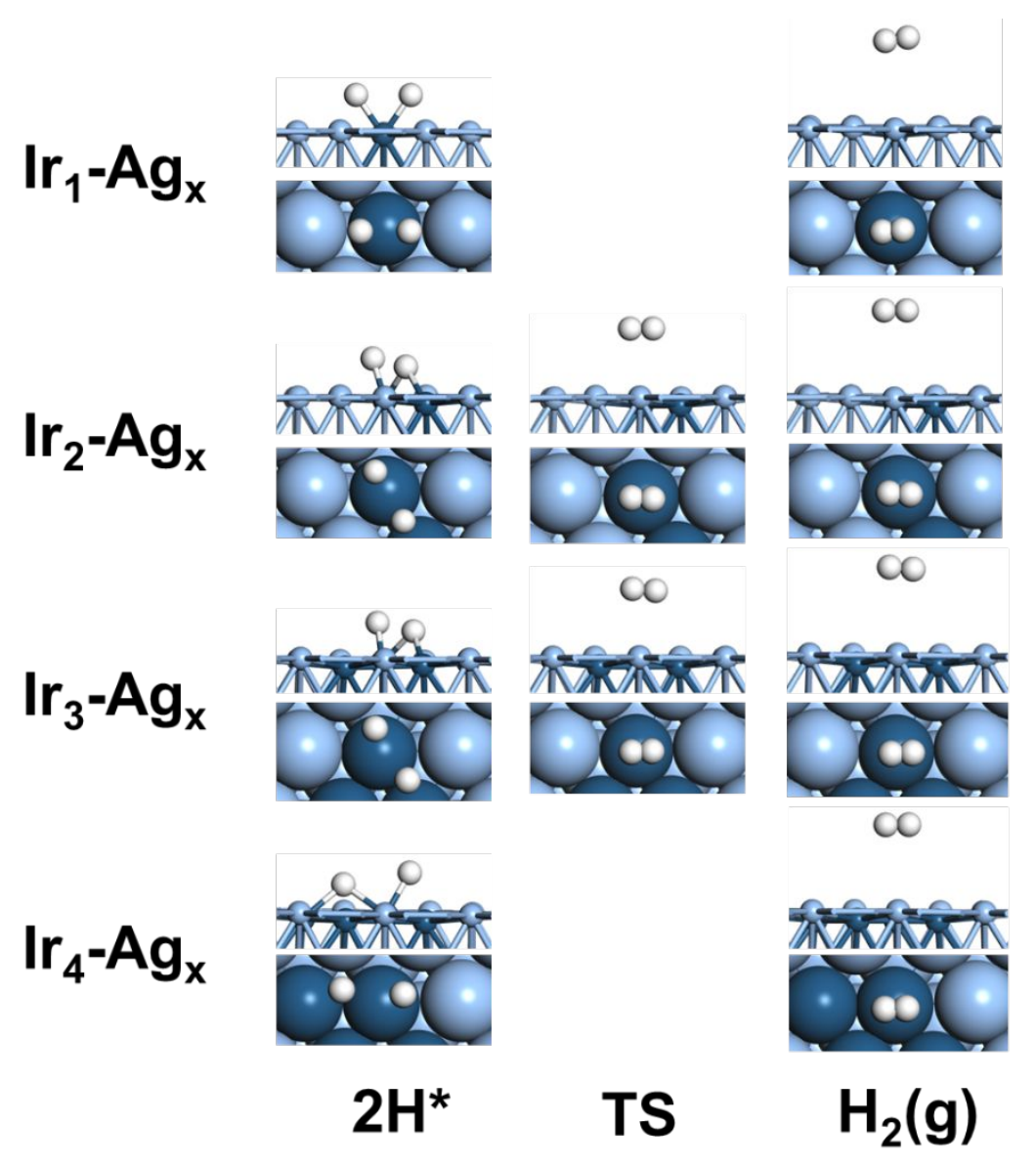

Figure S7. Hydrogen desorption pathways on Ir-Ag surfaces. Silver, deep blue, and white spheres represent $\mathrm{Ag}$, Ir, and $\mathrm{H}$, respectively. 

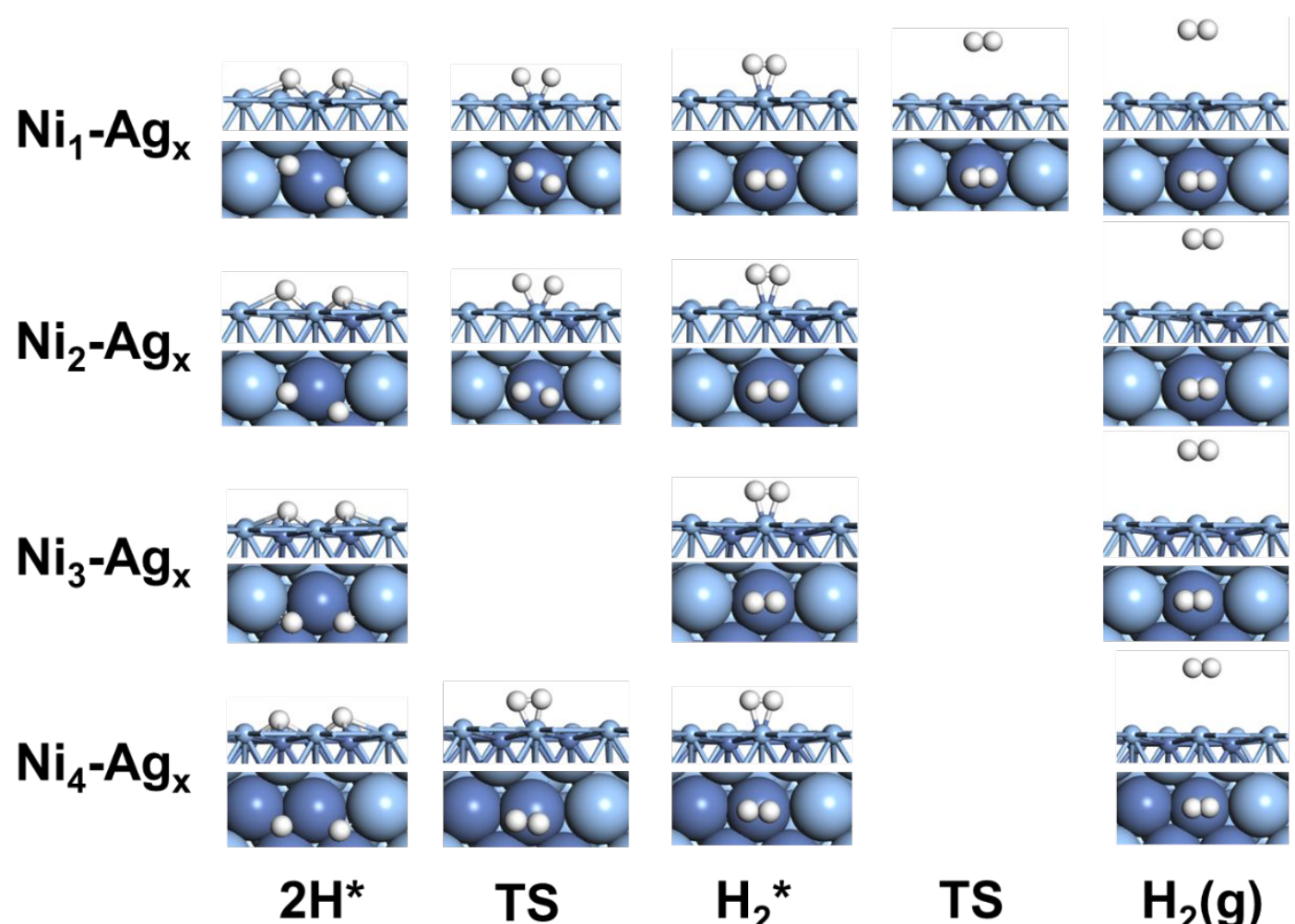

TS

$\mathrm{H}_{2}^{*}$

TS

$\mathrm{H}_{2}(\mathrm{~g})$

Figure S8. Hydrogen desorption pathways on Ni-Ag surfaces. Silver, purple, and white spheres represent $\mathrm{Ag}, \mathrm{Ni}$, and $\mathrm{H}$, respectively. 


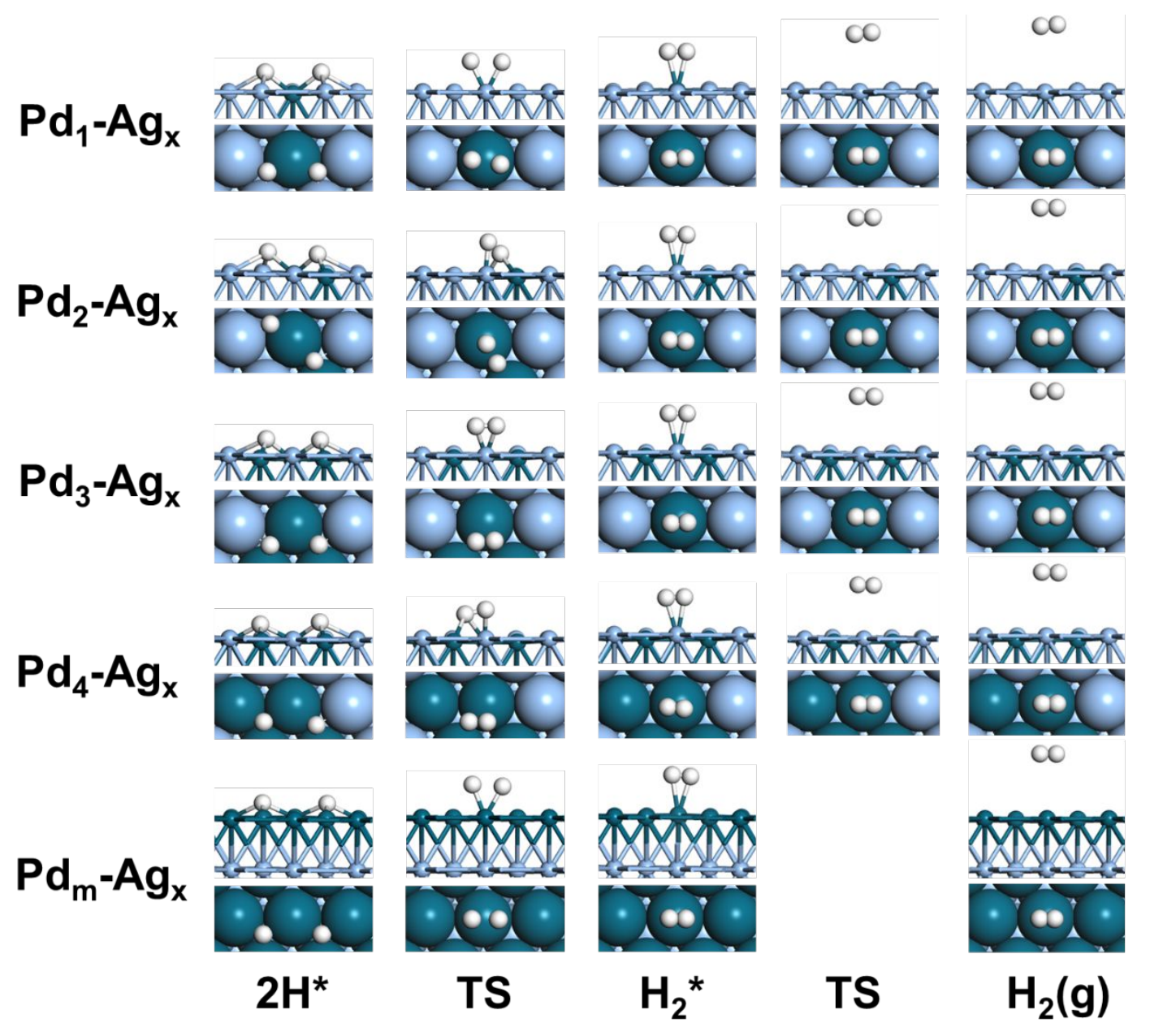

Figure S9. Hydrogen desorption pathways on Pd-Ag surfaces. Silver, deep green, and white spheres represent $\mathrm{Ag}, \mathrm{Pd}$, and $\mathrm{H}$, respectively. 


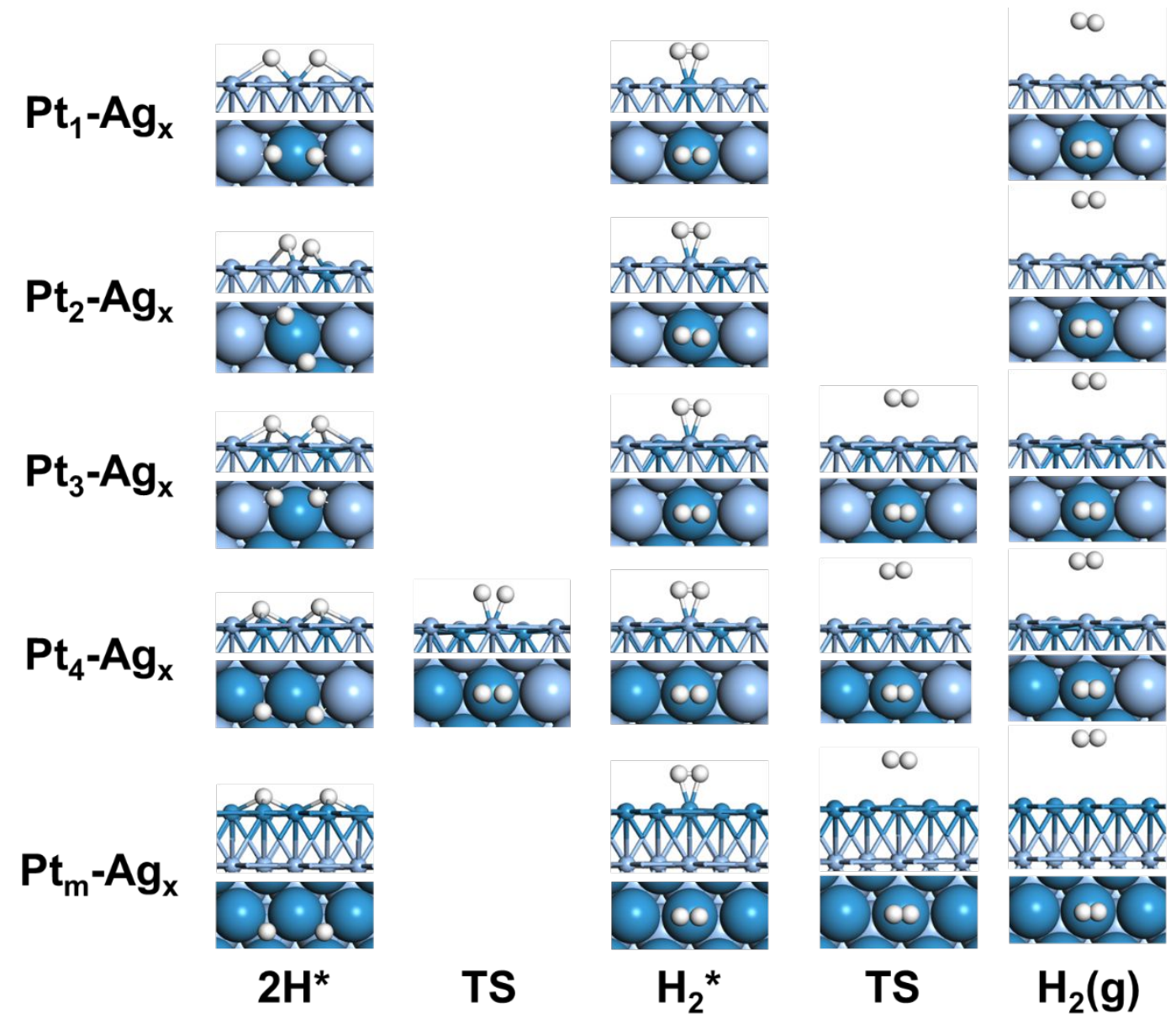

Figure S10. Hydrogen desorption pathways on Pt-Ag surfaces. Silver, blue, and white spheres represent $\mathrm{Ag}, \mathrm{Pt}$, and $\mathrm{H}$, respectively. 

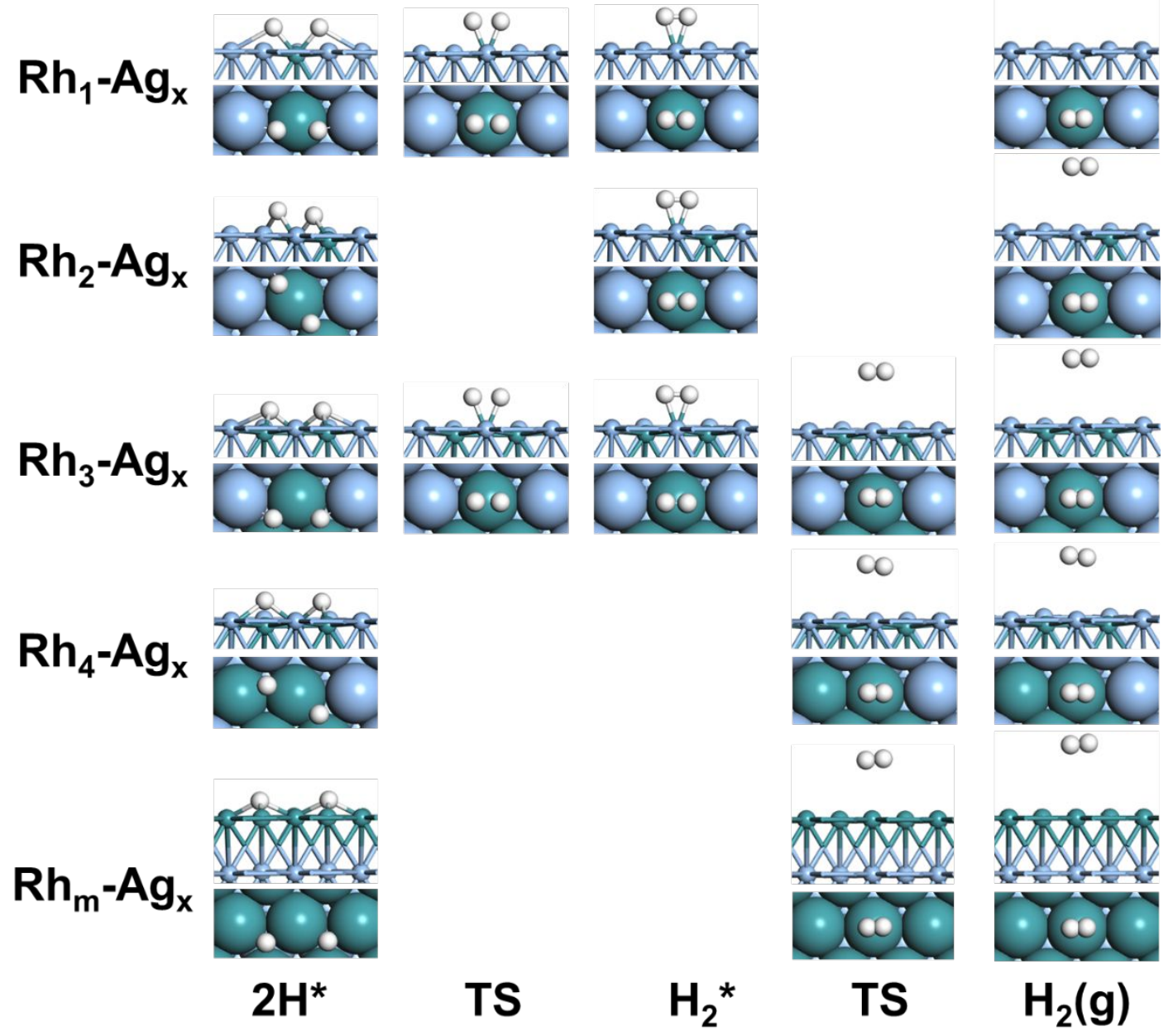

Figure S11. Hydrogen desorption pathways on Rh-Ag surfaces. Silver, green, and white spheres represent $\mathrm{Ag}, \mathrm{Rh}$, and $\mathrm{H}$, respectively. 

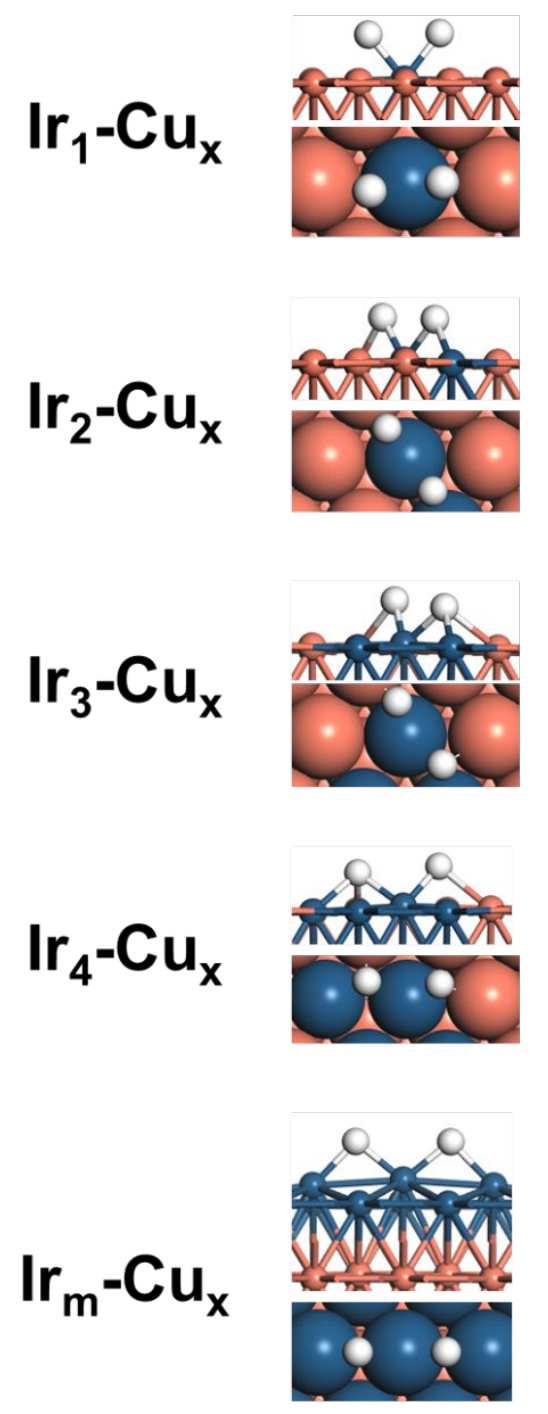

$2 \mathrm{H}^{*}$

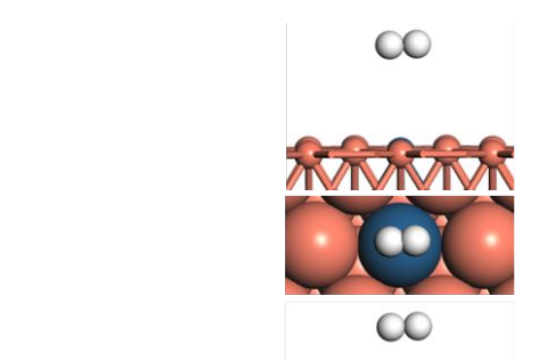

$\infty$

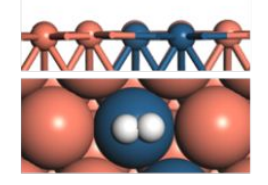

$\mathrm{CO}$
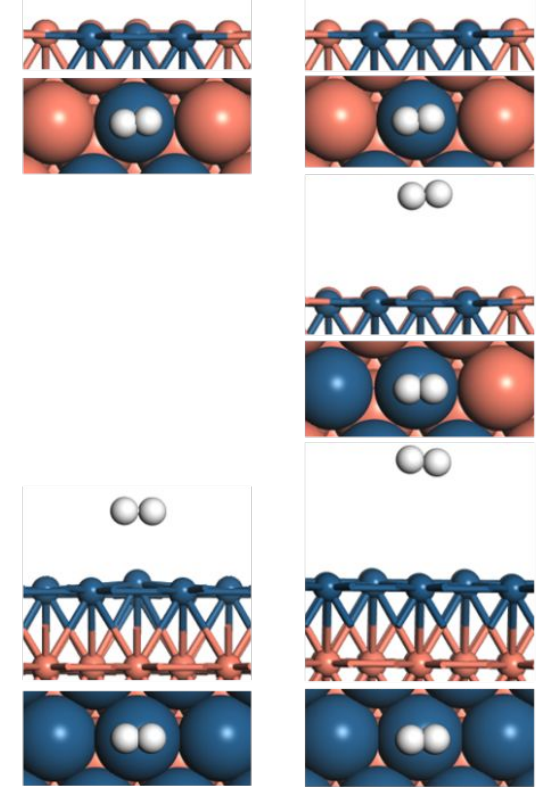

TS

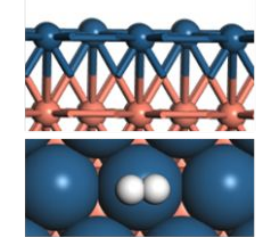

$\mathrm{H}_{\mathbf{2}}(\mathrm{g})$

Figure S12. Hydrogen desorption pathways on $\mathrm{Ir}-\mathrm{Cu}$ surfaces. Red, deep blue, and white spheres represent $\mathrm{Cu}$, Ir, and $\mathrm{H}$, respectively. 


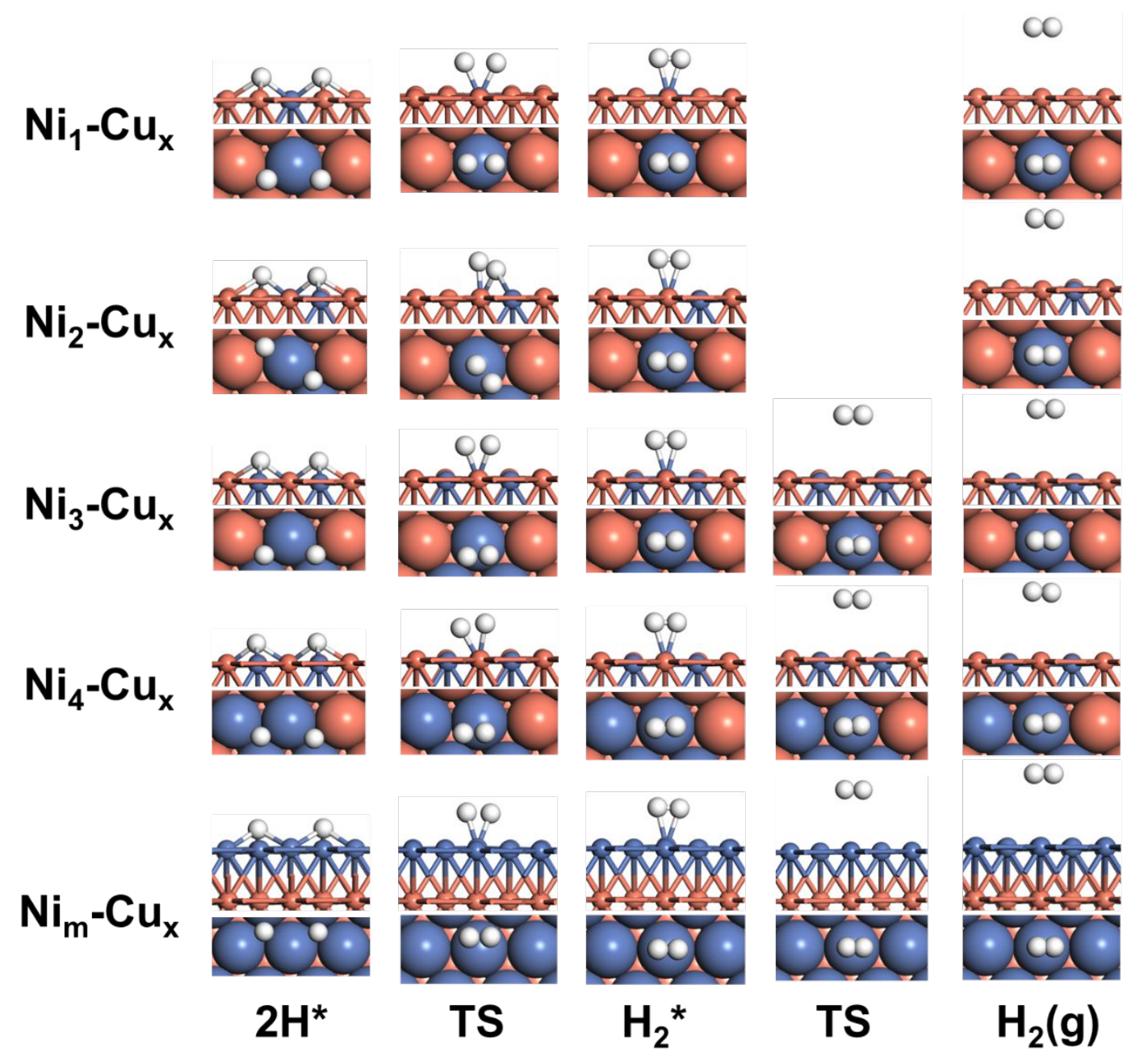

Figure S13. Hydrogen desorption pathways on Ni-Cu surfaces. Red, purple, and white spheres represent $\mathrm{Cu}, \mathrm{Ni}$, and $\mathrm{H}$, respectively. 

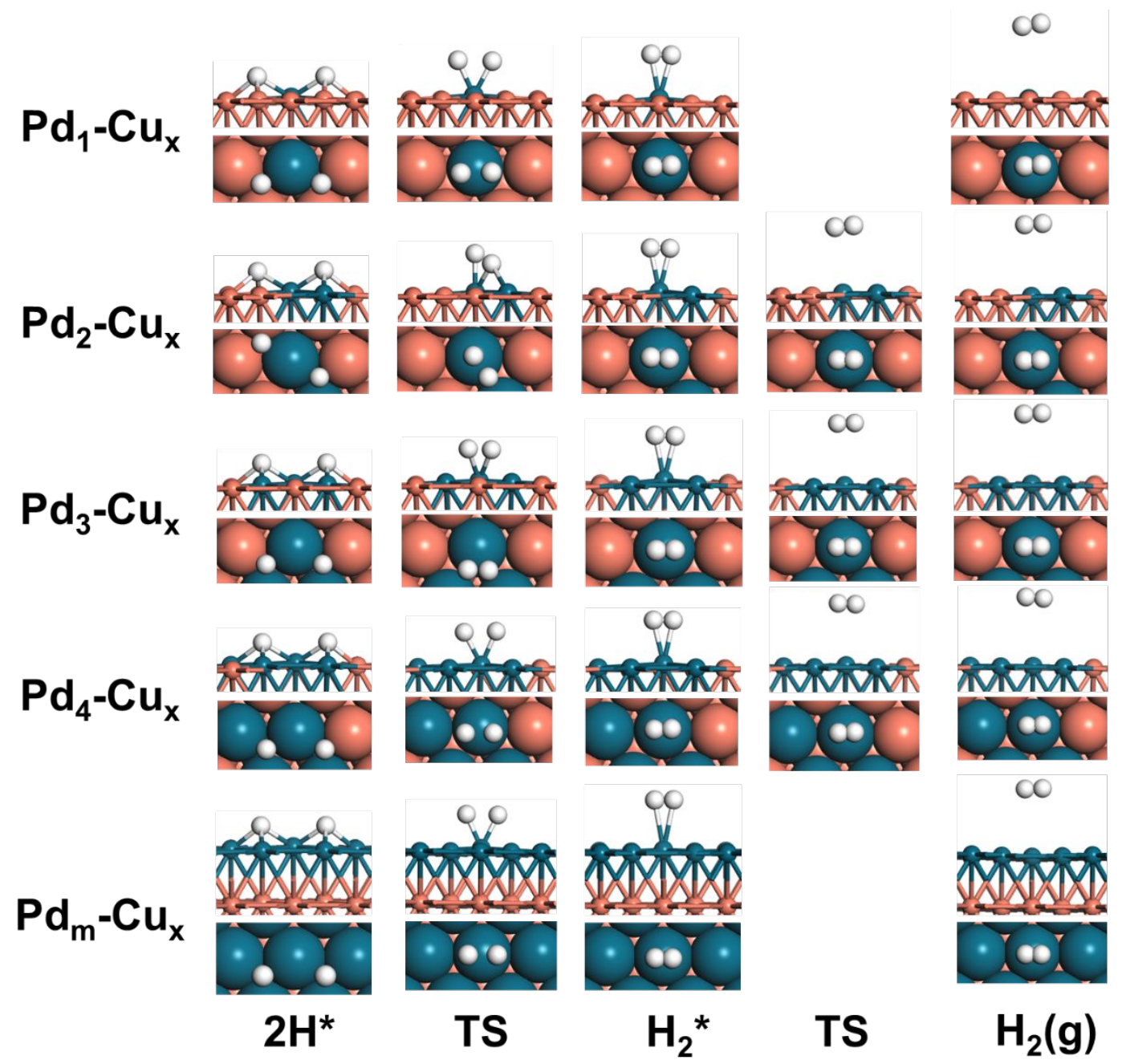

Figure S14. Hydrogen desorption pathways on Pd-Cu surfaces. Red, deep green, and white spheres represent $\mathrm{Cu}, \mathrm{Pd}$, and $\mathrm{H}$, respectively. 


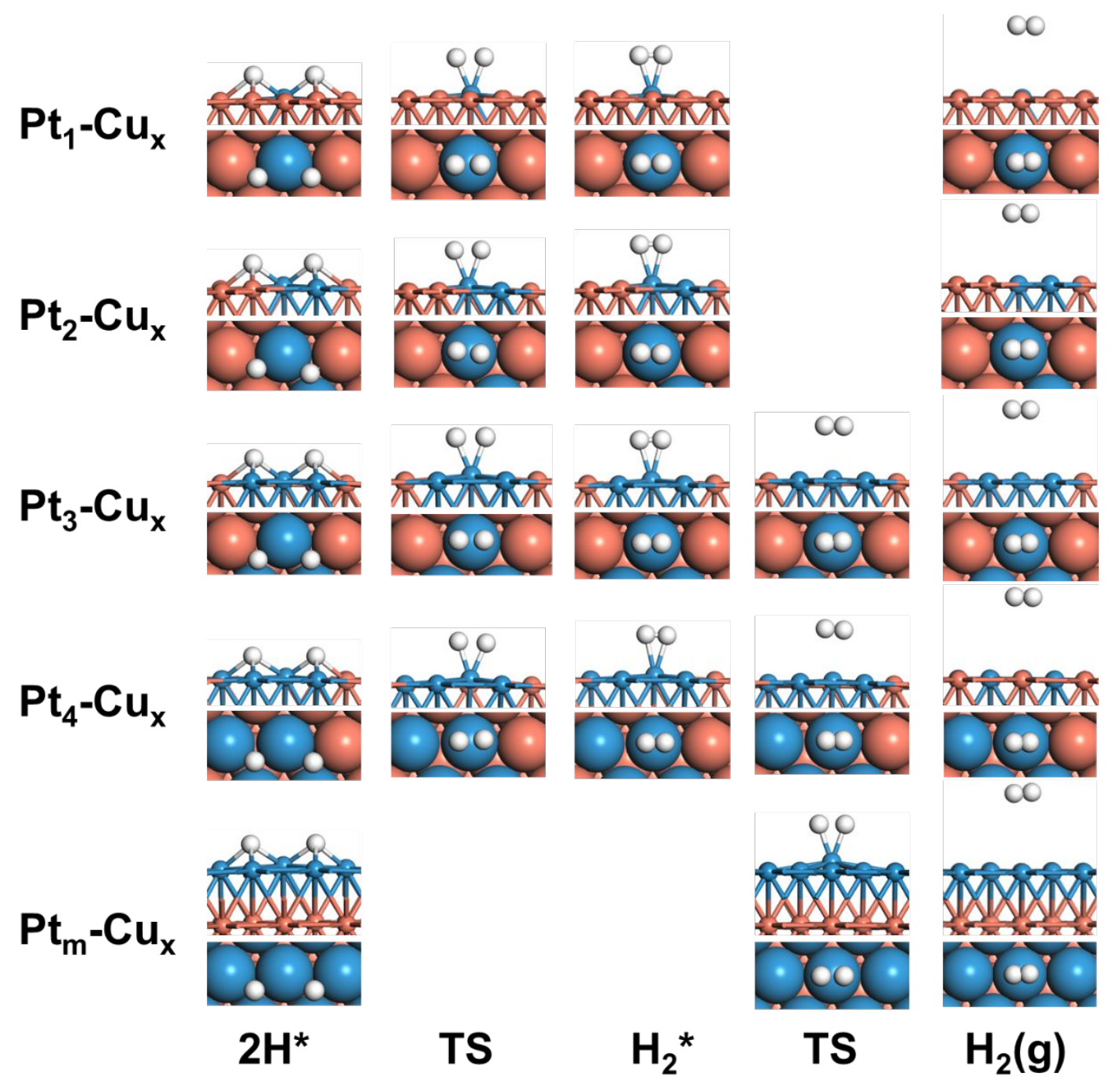

Figure S15. Hydrogen desorption pathways on Pt-Cu surfaces. Red, blue, and white spheres represent $\mathrm{Cu}, \mathrm{Pt}$, and $\mathrm{H}$, respectively. 


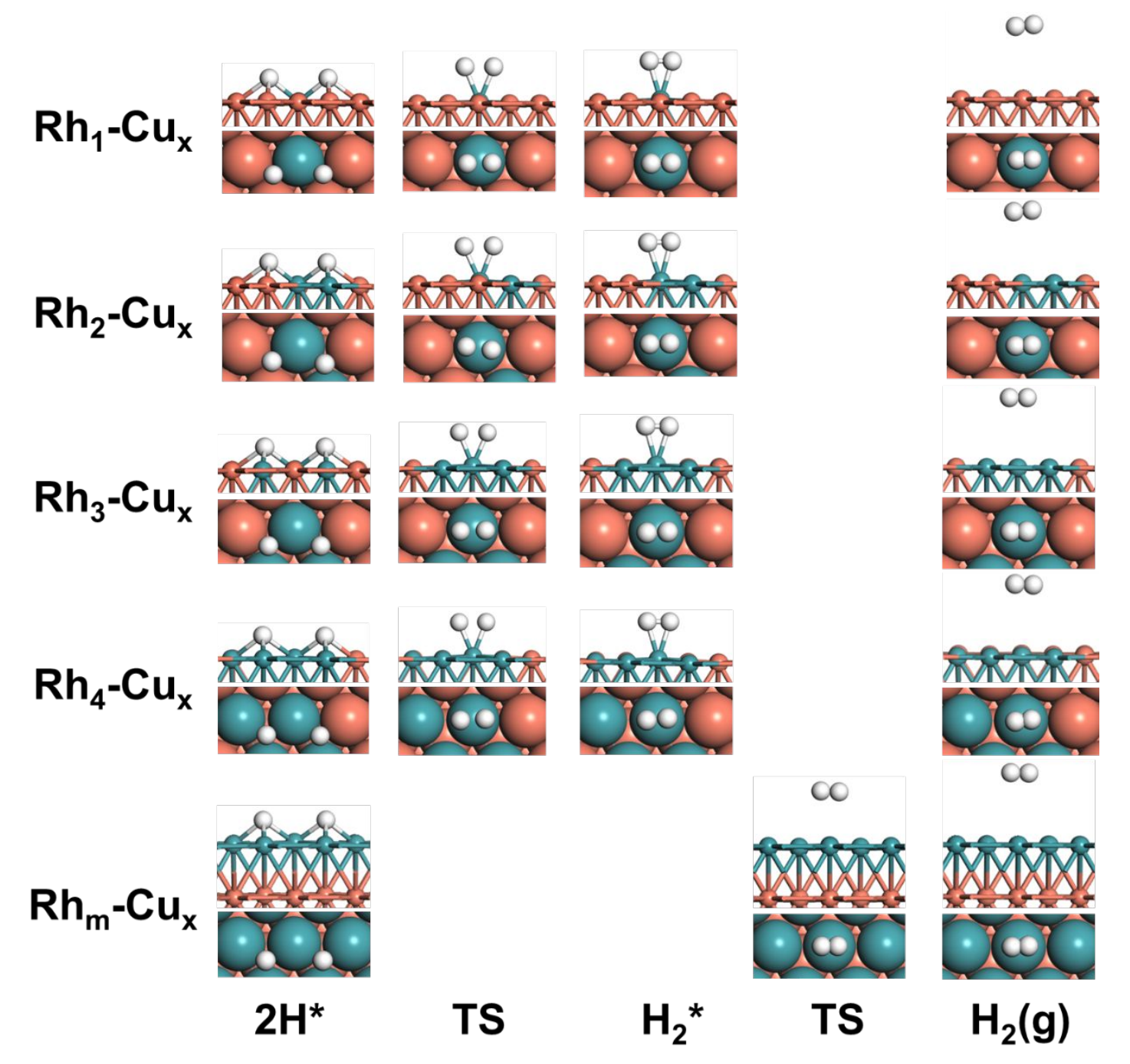

Figure S16. Hydrogen desorption pathways on $\mathrm{Rh}-\mathrm{Cu}$ surfaces. Red, green, and white spheres represent $\mathrm{Cu}, \mathrm{Rh}$, and $\mathrm{H}$, respectively. 

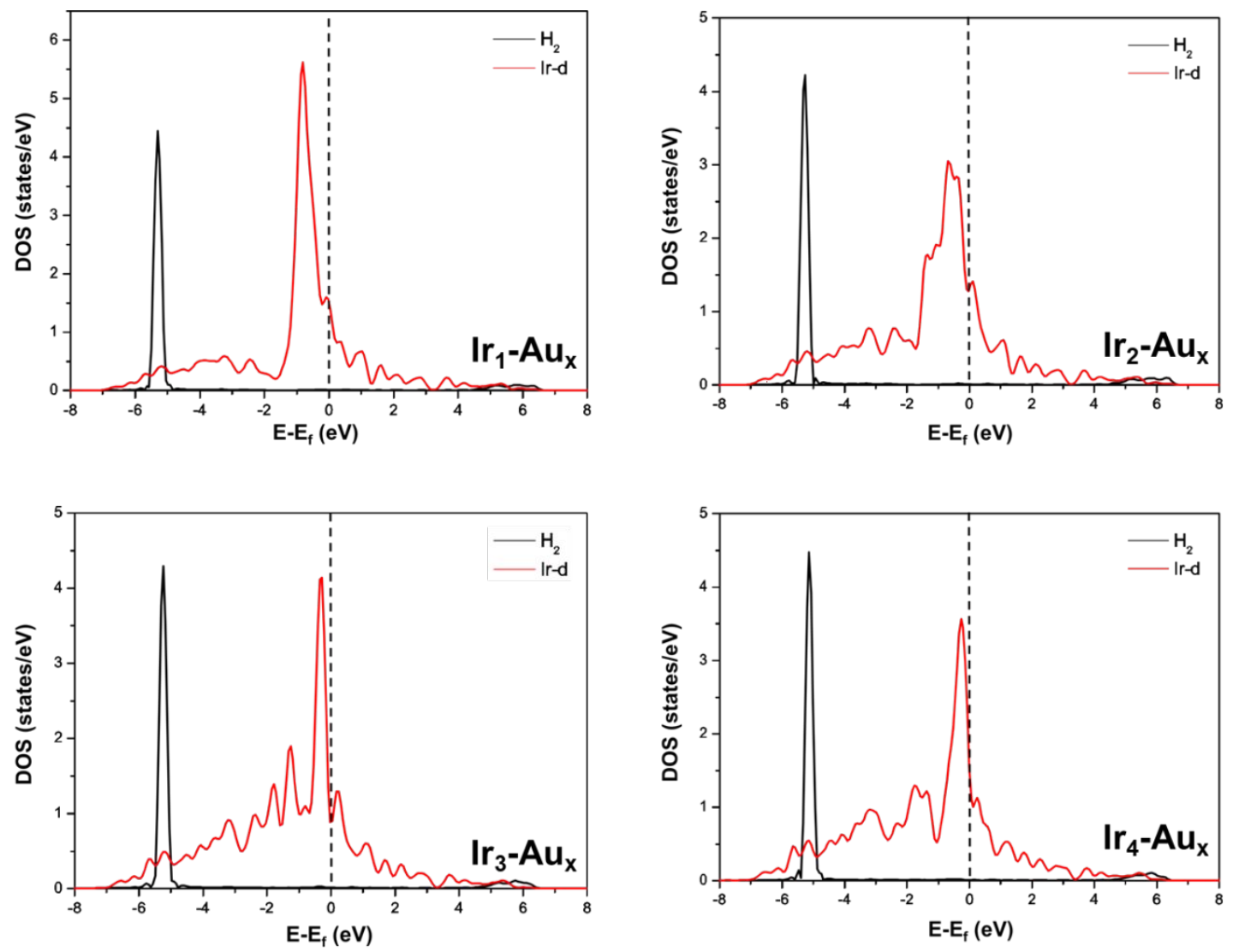

Figure S17. Projected density of states (PDOS) of gas-phase $\mathrm{H}_{2}$ and the $d$-orbital of an Ir atom in a $\mathrm{Au}$ surface. 

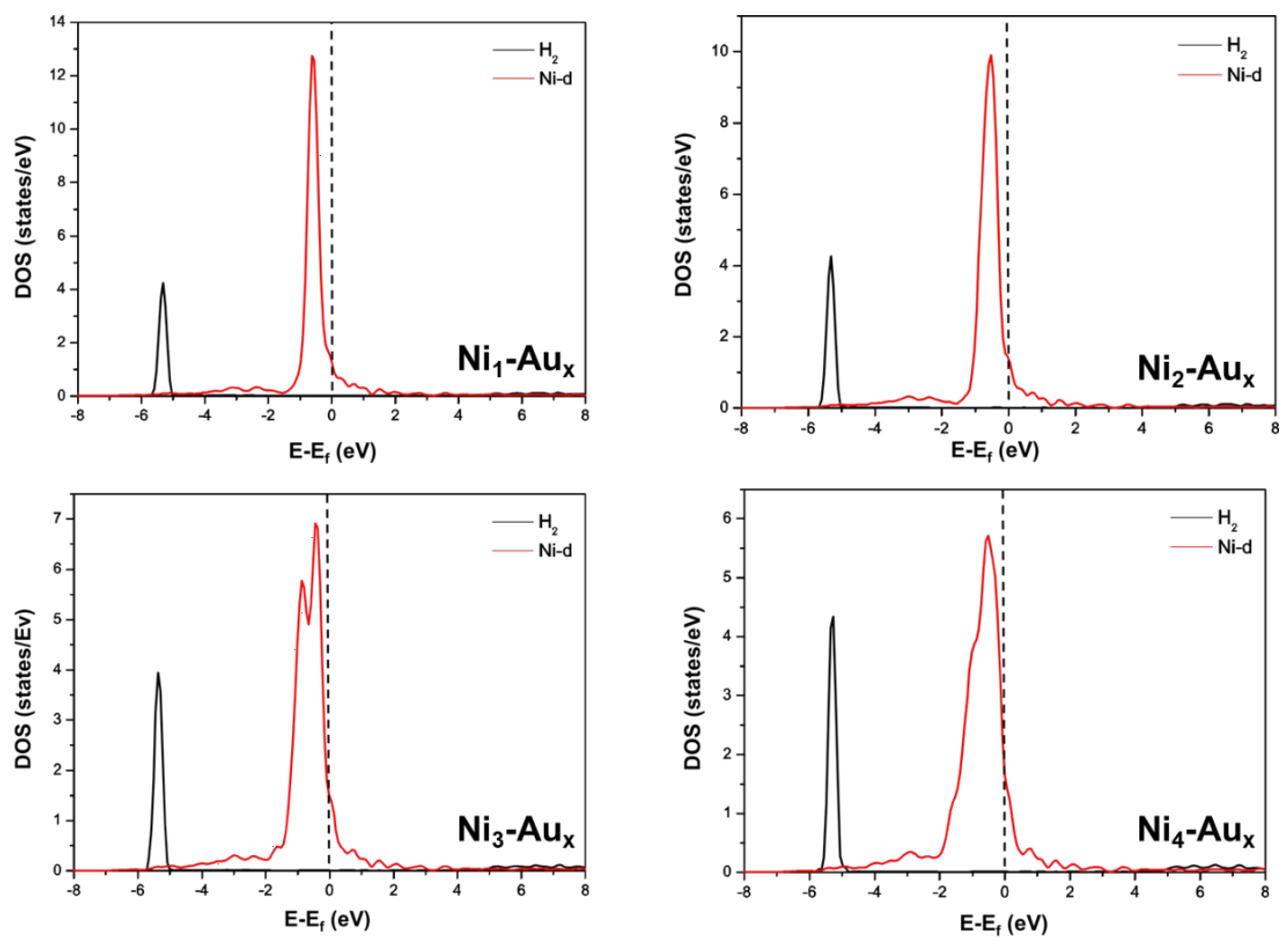

Figure S18. PDOS of gas-phase $\mathrm{H}_{2}$ and the $d$-orbital of a Ni atom in a Au surface. 

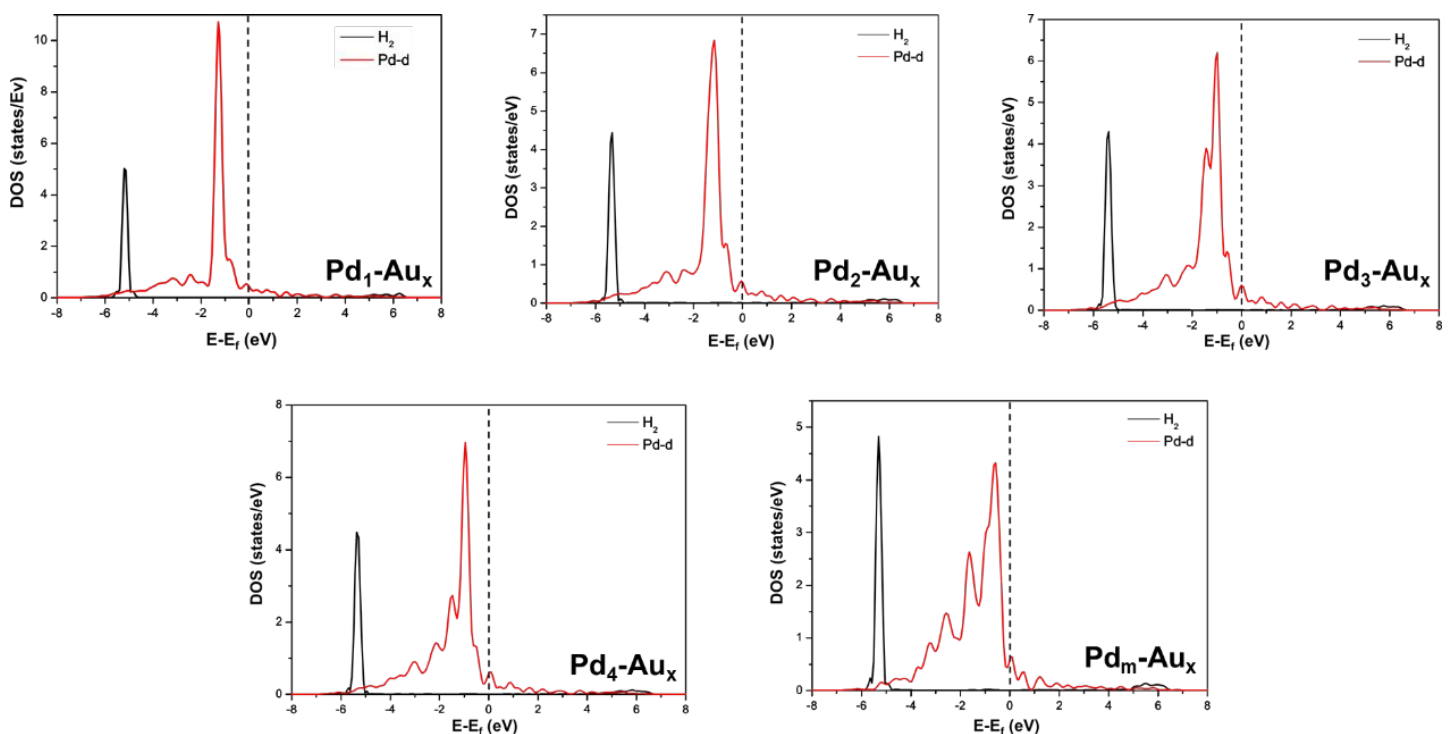

Figure S19. PDOS of gas-phase $\mathrm{H}_{2}$ and the $d$-orbital of a Pd atom in a Au surface. 

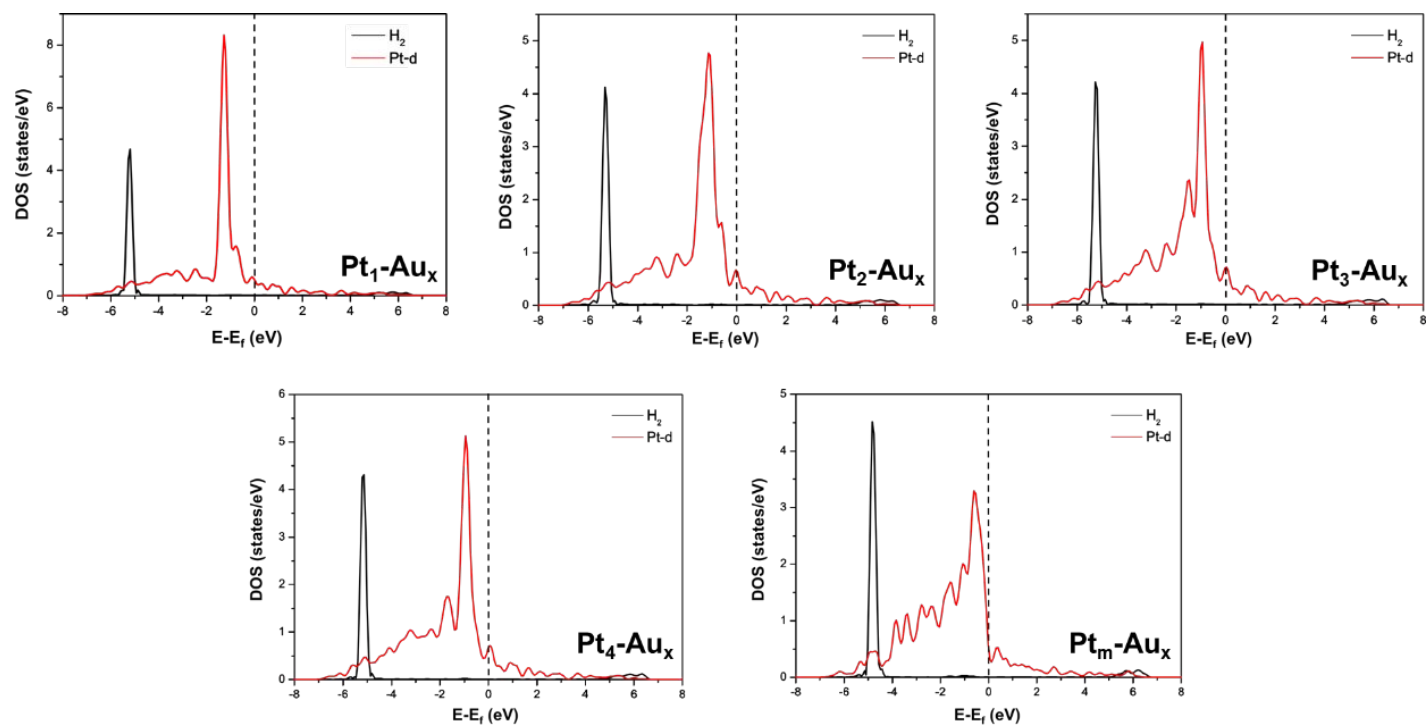

Figure S20. PDOS for gas-phase $\mathrm{H}_{2}$ and the $d$-orbital of a $\mathrm{Pt}$ atom in a Au surface. 

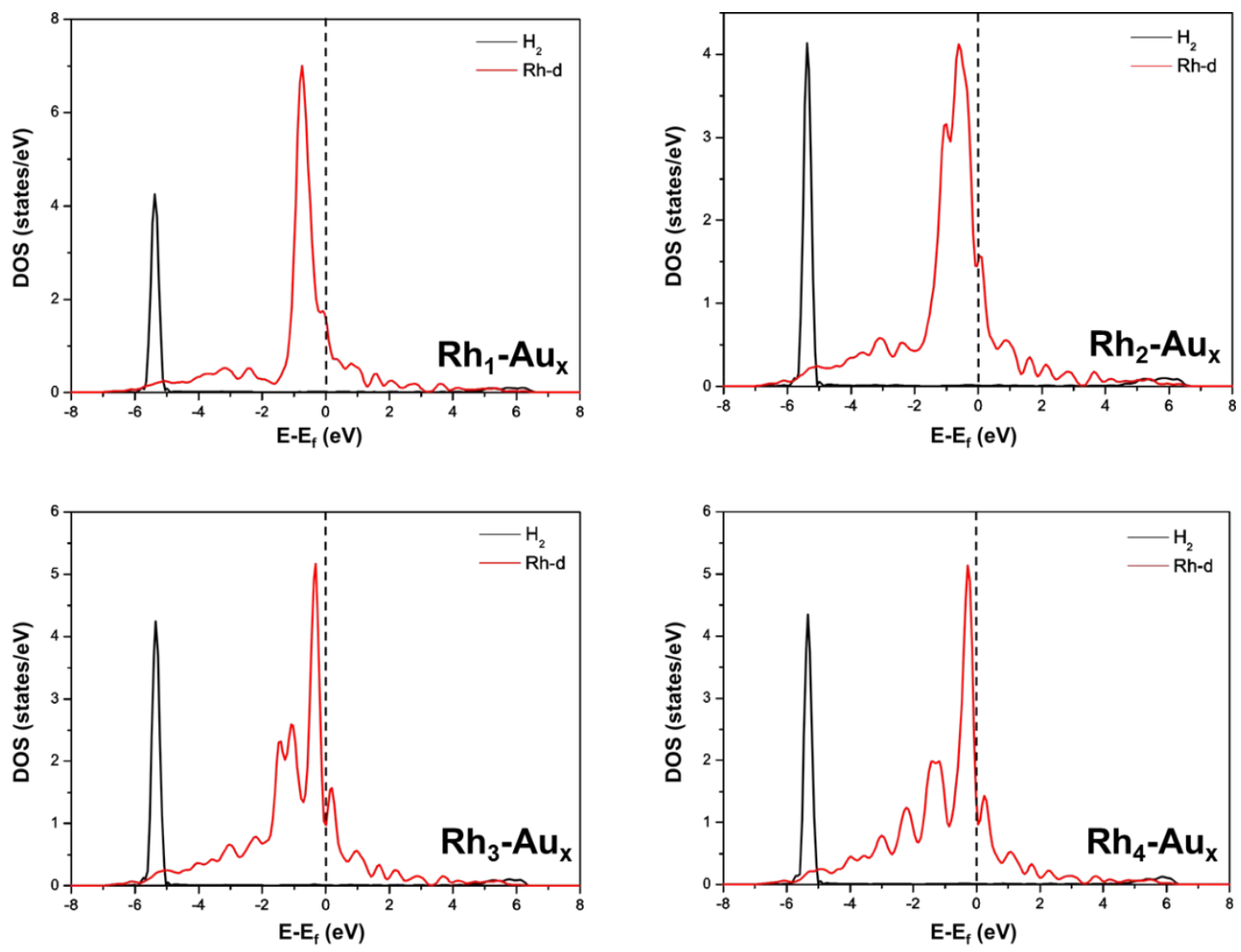

Figure S21. PDOS of gas-phase $\mathrm{H}_{2}$ and $d$-orbital of a $\mathrm{Rh}$ atom in a $\mathrm{Au}$ surface. 

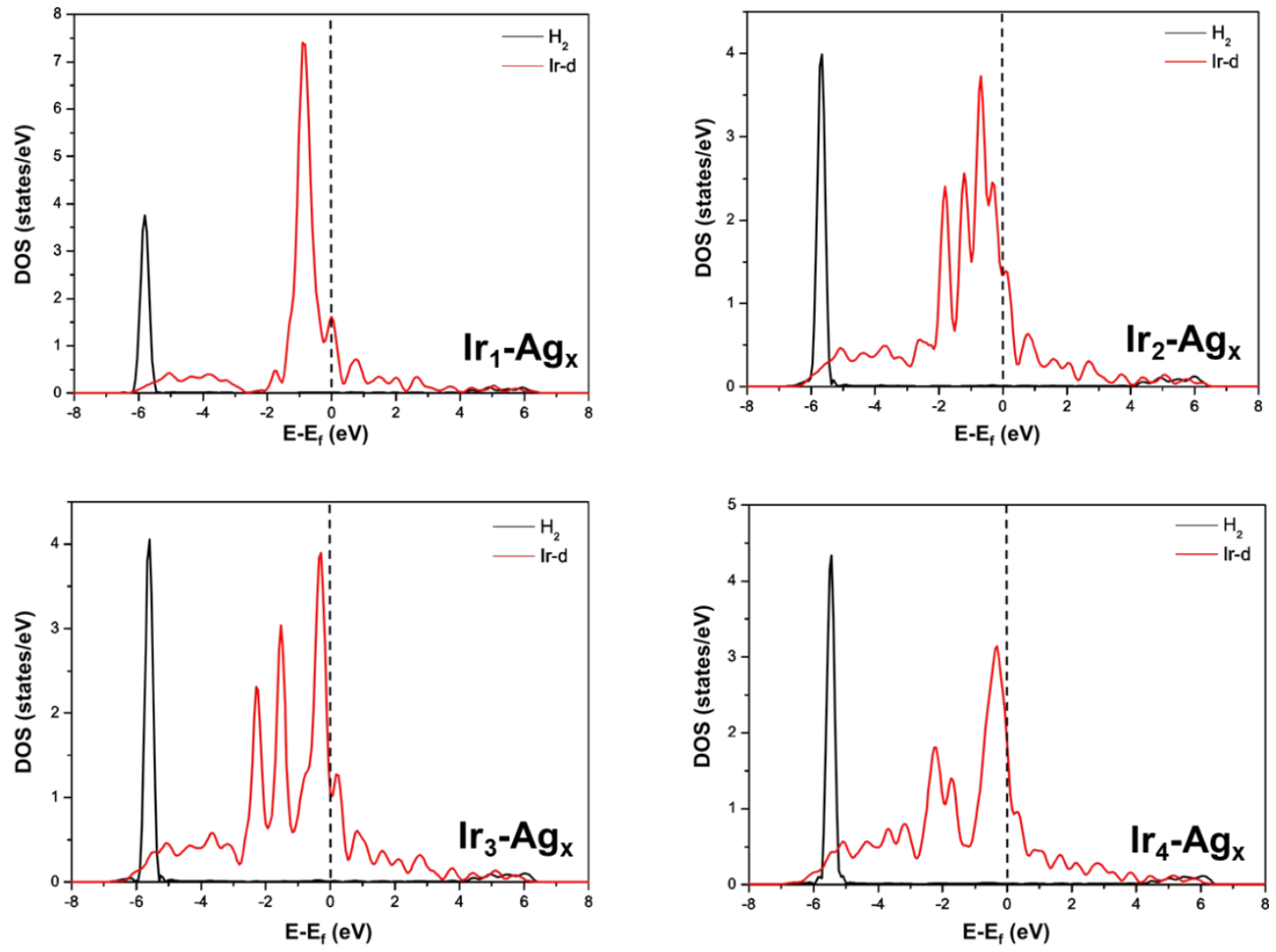

Figure S22. PDOS of gas-phase $\mathrm{H}_{2}$ and $d$-orbital of a Ir atom in a Ag surface. 

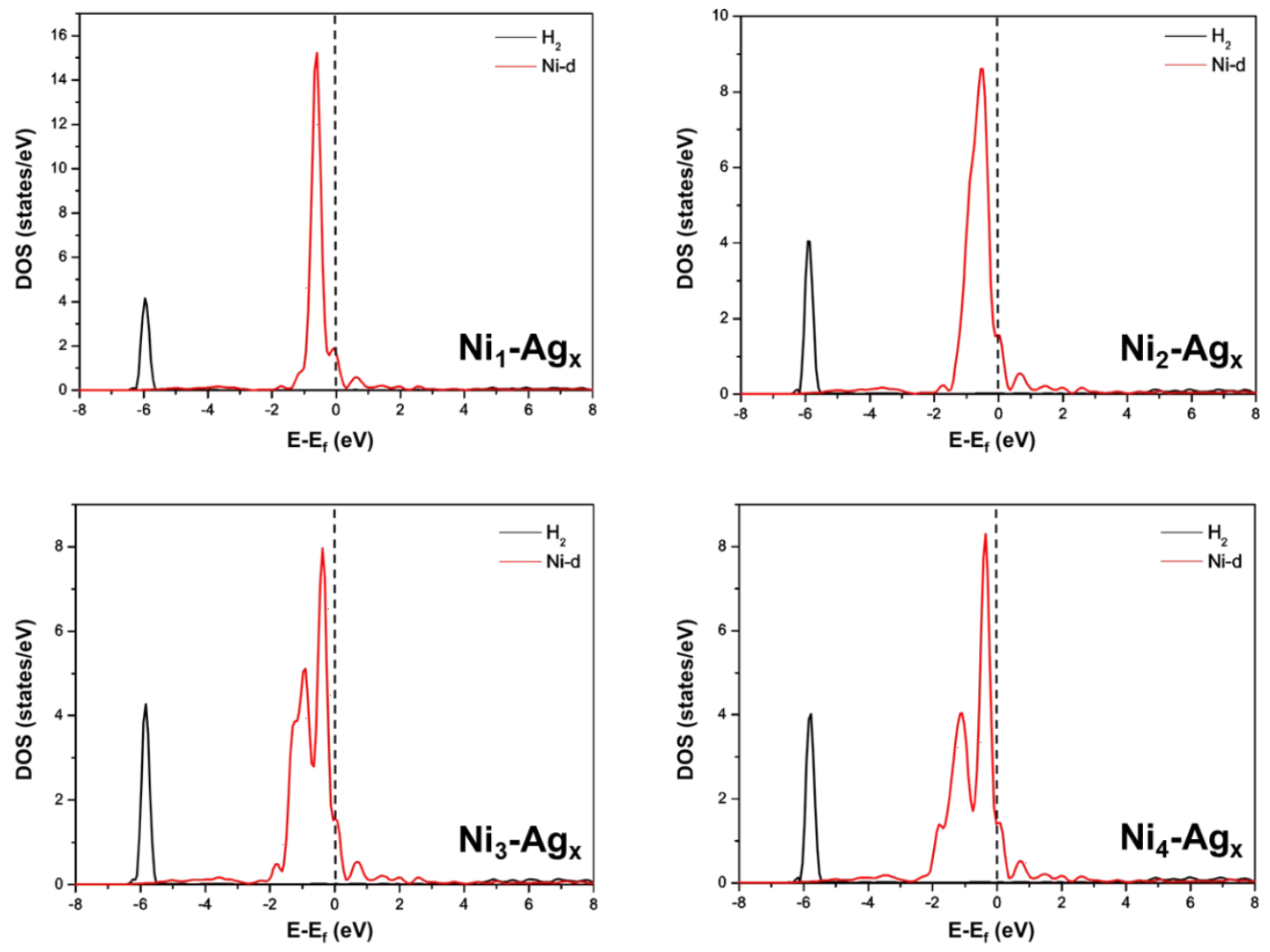

Figure S23. PDOS of gas-phase $\mathrm{H}_{2}$ and $d$-orbital of a Ni atom in a $\mathrm{Ag}$ surface. 

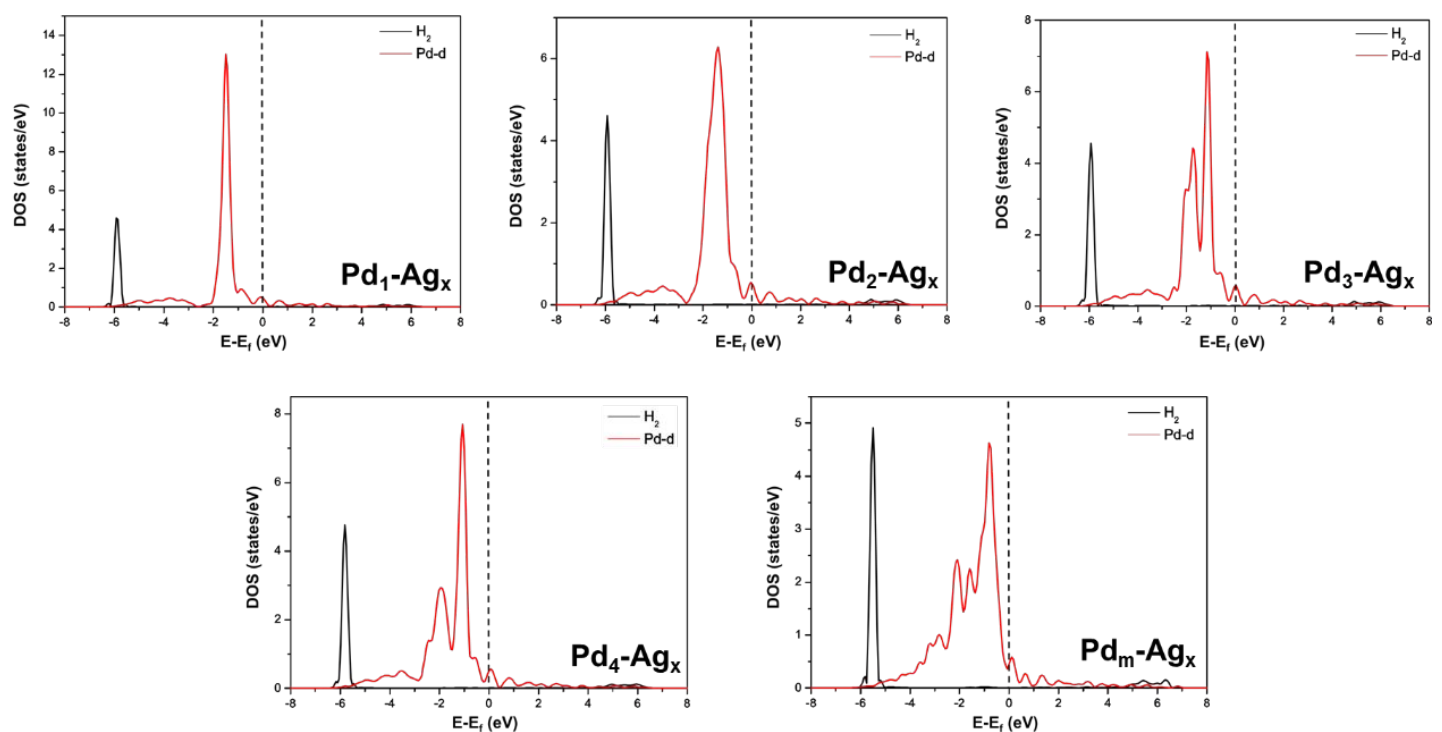

Figure S24. PDOS of gas-phase $\mathrm{H}_{2}$ and the $d$-orbital of a Pd atom in a $\mathrm{Ag}$ surface. 

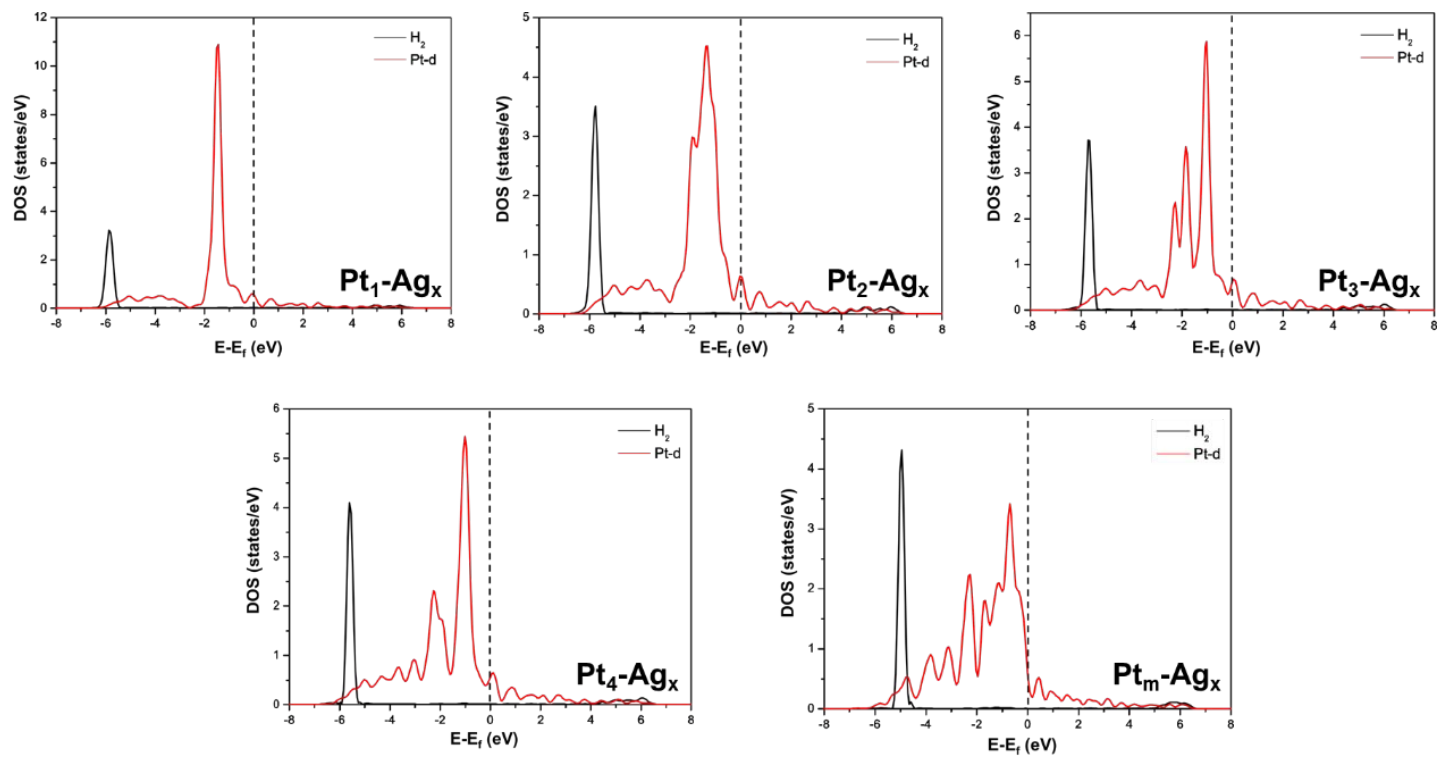

Figure S25. PDOS of gas-phase $\mathrm{H}_{2}$ and the $d$-orbital of a Pt atom in a Ag surface. 

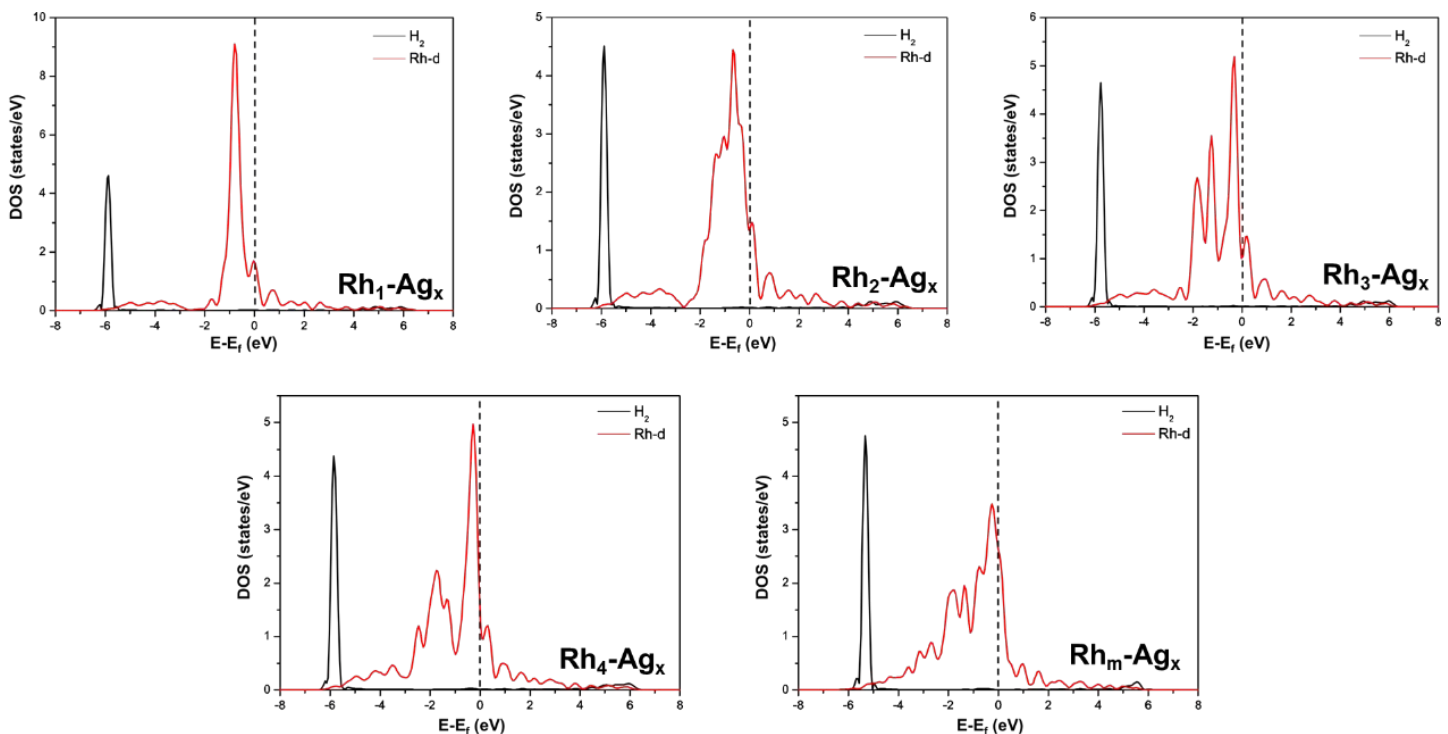

Figure S26. PDOS of gas-phase $\mathrm{H}_{2}$ and the $d$-orbital of a $\mathrm{Rh}$ atom in a $\mathrm{Ag}$ surface. 

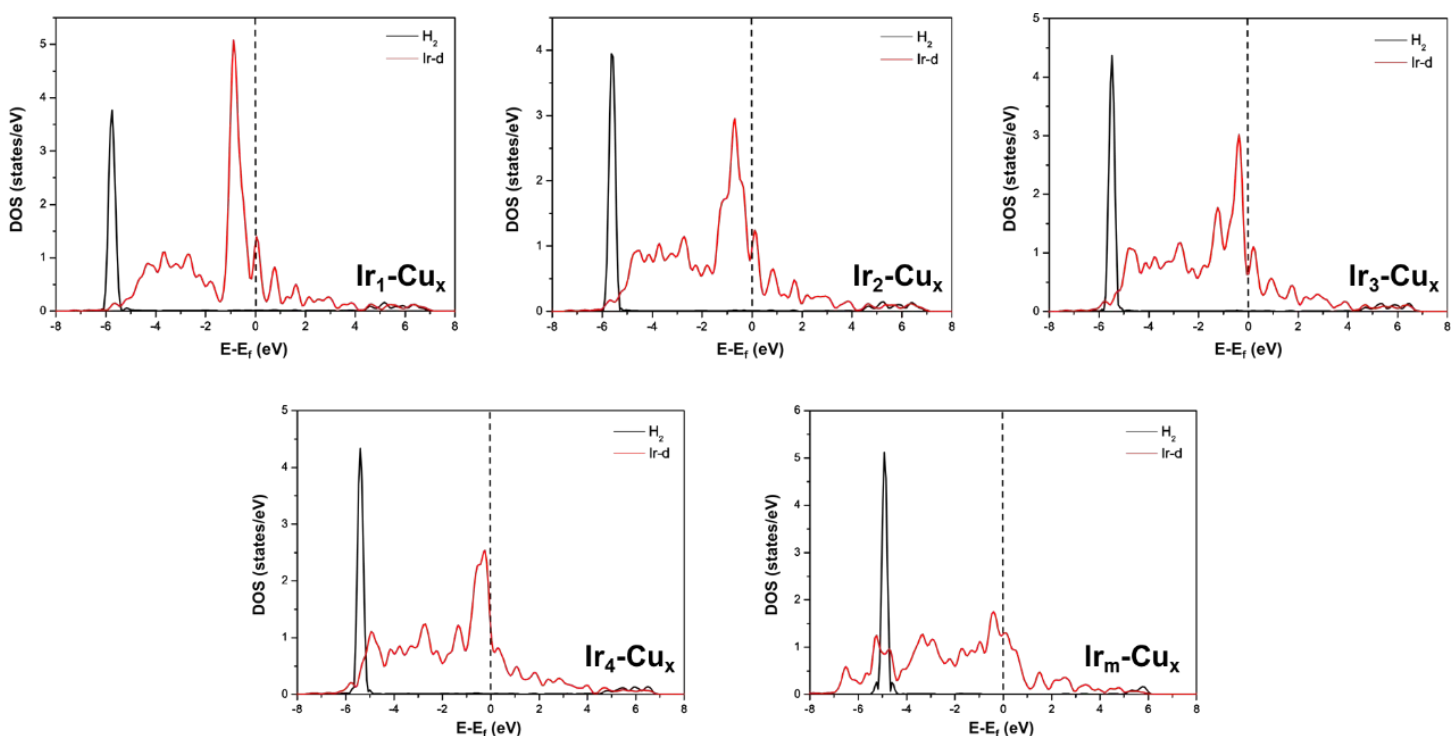

Figure S27. PDOS of gas-phase $\mathrm{H}_{2}$ and the $d$-orbital of an $\mathrm{Ir}$ atom in a $\mathrm{Cu}$ surface. 

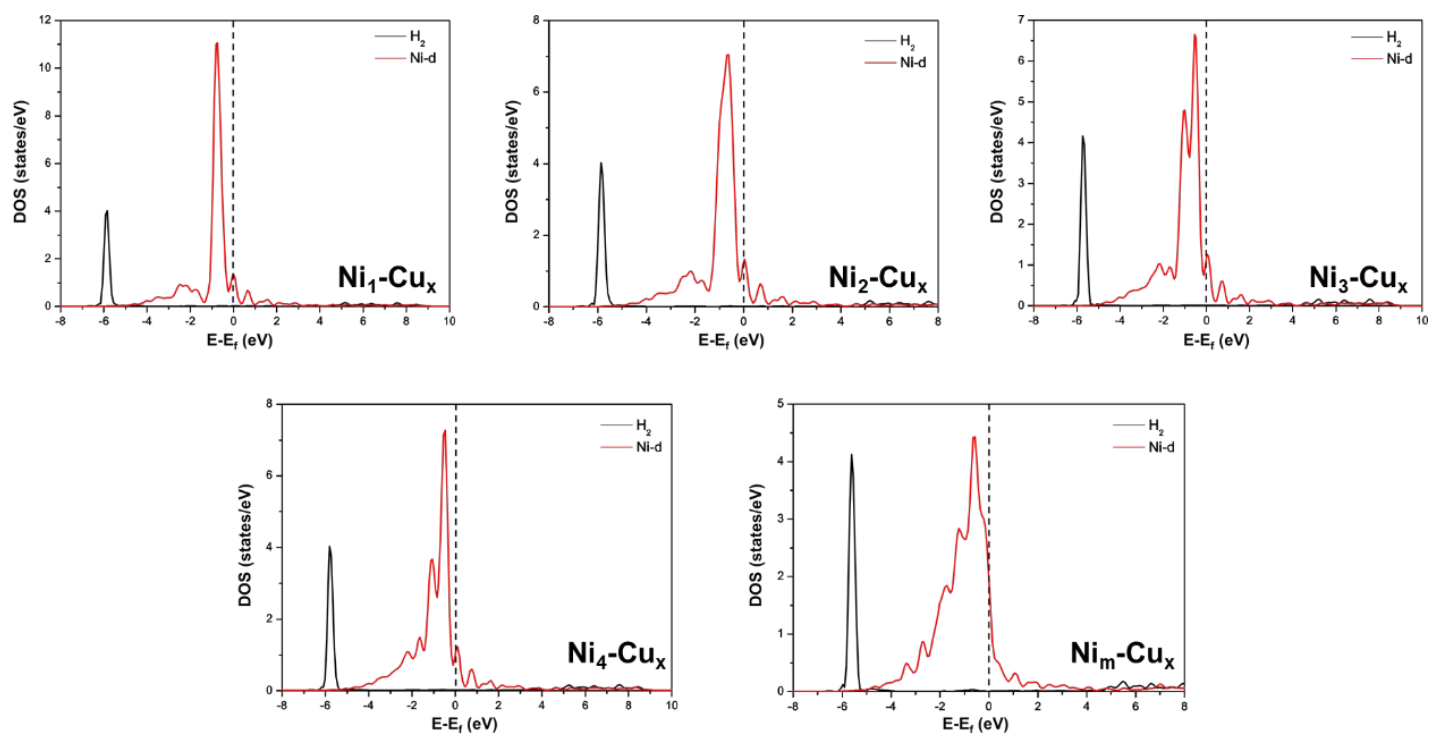

Figure S28. PDOS of gas-phase $\mathrm{H}_{2}$ and the $d$-orbital of a $\mathrm{Ni}$ atom in a $\mathrm{Cu}$ surface. 

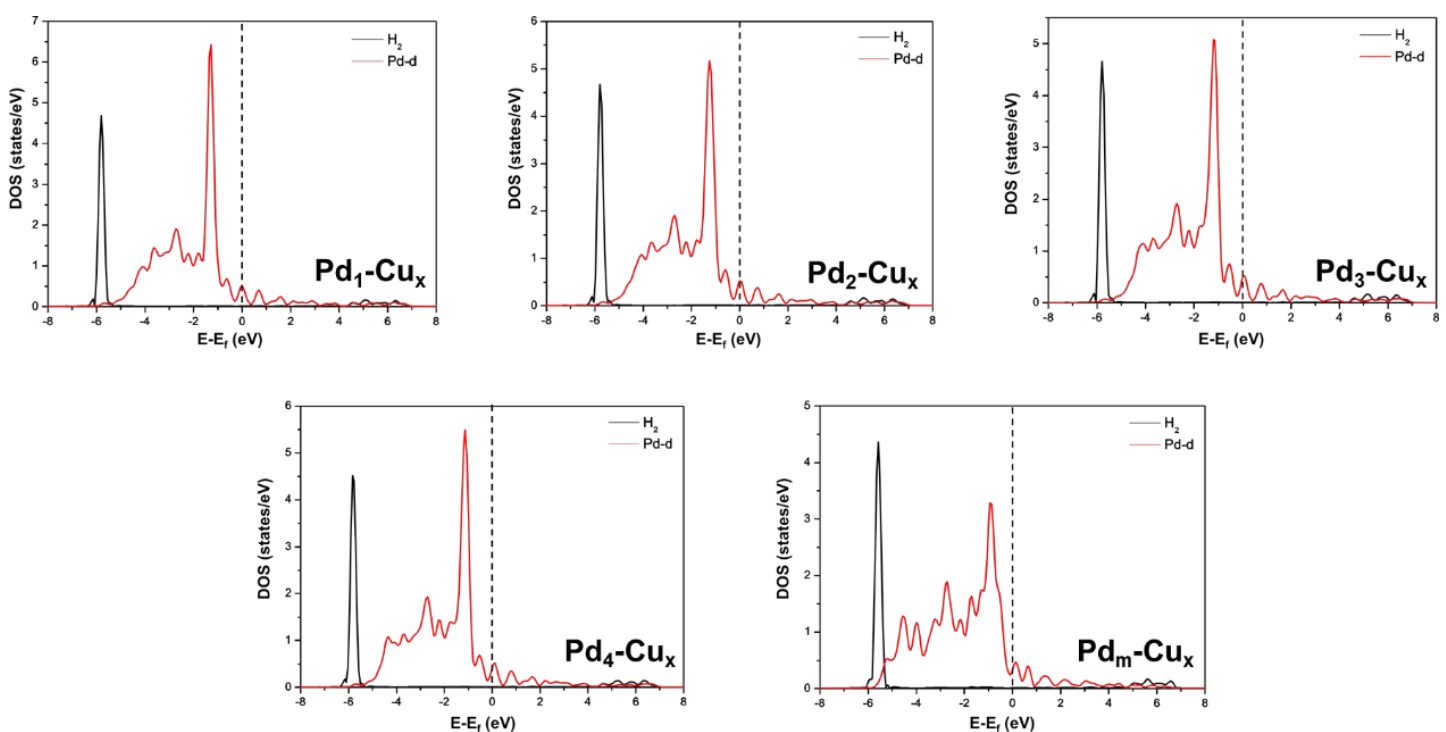

Figure S29. PDOS of gas-phase $\mathrm{H}_{2}$ and the $d$-orbital of a $\mathrm{Pd}$ atom in a $\mathrm{Cu}$ surface. 

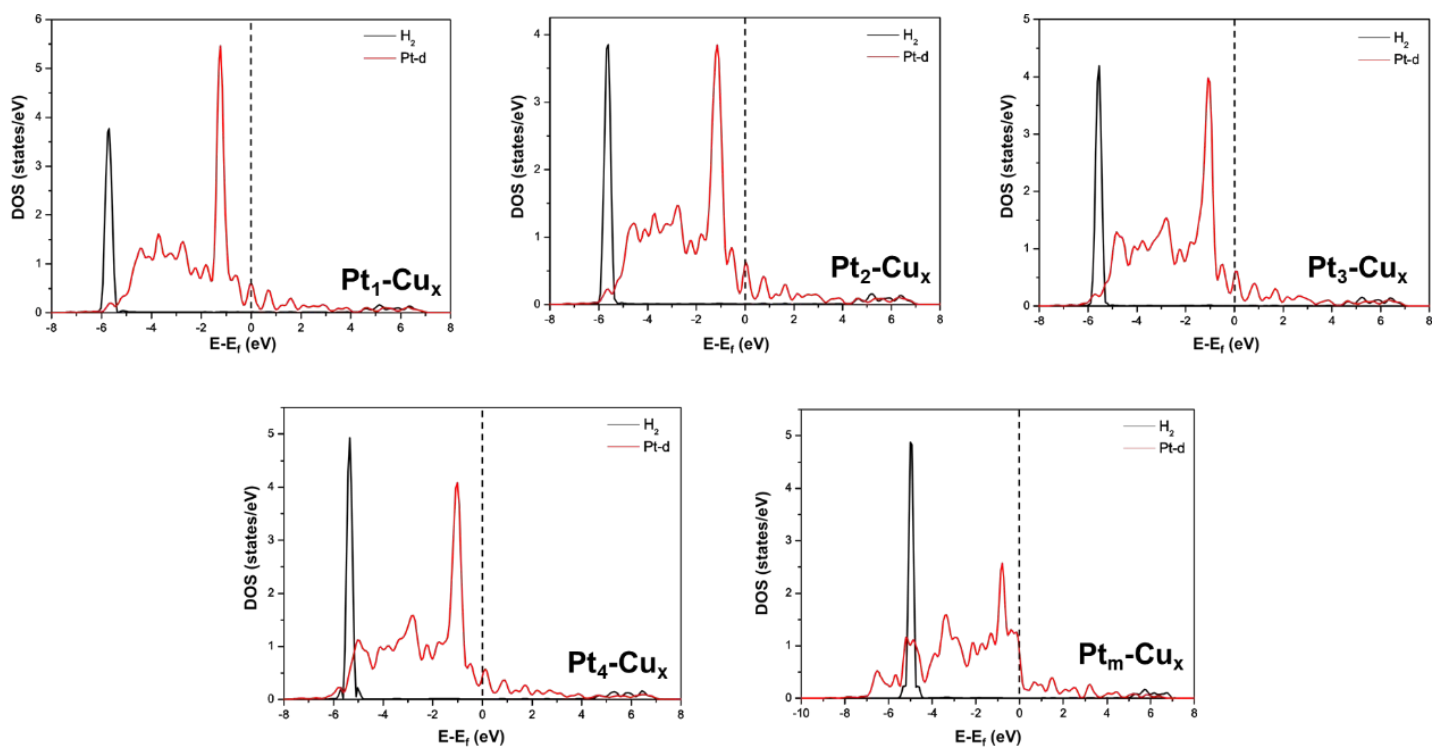

Figure S30. PDOS of gas-phase $\mathrm{H}_{2}$ and the $d$-orbital of a Pt atom in a $\mathrm{Cu}$ surface. 

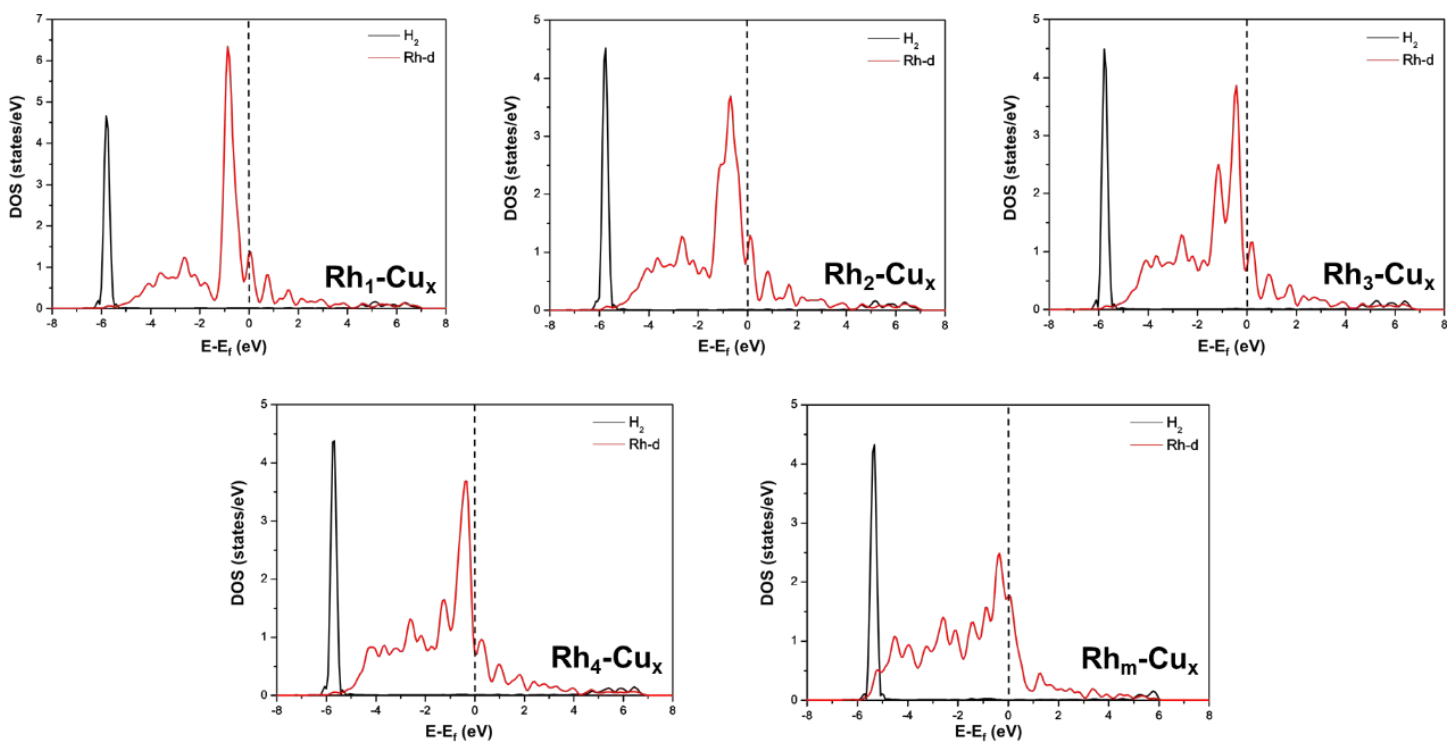

Figure S31. PDOS of gas-phase $\mathrm{H}_{2}$ and the $d$-orbital of a $\mathrm{Rh}$ atom in a $\mathrm{Cu}$ surface. 